\title{
WAVES OF ACCELERATED MOTION IN A GLACIER APPROACHING SURGE: THE MINI-SURGES OF VARIEGATED GLACIER, ALASKA, U.S.A.*
}

\author{
By BARCLAY KAMB \\ (Division of Geological and Planetary Sciences, California Institute of Technology, Pasadena, California \\ 91125 , U.S.A.) \\ and HERMANN ENGELHARDT \\ (Institut für Geophysik, Westfälische Wilhelmsuniversität, D-4400 Münster, Federal Republic of Germany)
}

\begin{abstract}
ABSTR.ACT. Periods of dramatically accelerated motion, in which the flow velocity increases suddenly from about $55 \mathrm{~cm} / \mathrm{d}$ to a peak of $100-300 \mathrm{~cm} / \mathrm{d}$ and then decreases gradually over the course of a day, occurred repeatedly during June and July 1978-81 in Variegated Glacier (Alaska), a surging-type glacier that surged in 1982-83. These "mini-surges" appear to be related mechanistically to the main surge. The flow-velocity peak propagates downglacier as a wave at a speed of about $0.3 \mathrm{~km} / \mathrm{h}$, over a reach of about $6 \mathrm{~km}$ in length. It is accompanied by a propagating pressure wave in the basal water system of the glacier, in which, after a preliminary drop, the pressure rises rapidly to a level greater than the ice-overburden pressure at the glacier bed, and then drops gradually over a period of 1-2d, usually reaching a new low for the summer. The peak velocity is accompanied by a peak of high seismic activity due to widespread fresh crevassing. It is also accompanied by a rapid uplift of the glacier surface, amounting to $6-11 \mathrm{~cm}$, which then relaxes over a period of $1-2$ d. Maximum uplift rate coincides with the peak in flow velocity; the peak in accumulated uplift lags behind the velocity peak by $2 \mathrm{~h}$. The uplift is mainly due to basal cavitation driven by the high basal water pressure, although the strain wave associated with the mini-surge motion can also contribute. Basal cavitation is probably responsible for the pulse of high turbidity that appears in the terminal outflow stream in association with each mini-surge. In the down-glacier reach, where the mini-surge waves are attenuating, the observed strain wave corresponds to what is expected for the propagating pulse in flow velocity, but in the reach of maximum mini-surge motion the strain wave has a form quite different, possibly related to special features in the mini-surge initiation process from that point up-stream. The flow acceleration in the mini-surges is due to enhanced basal sliding caused by the high basal water pressure and the consequent reduction of bed friction. A preliminary velocity increase shortly before the pressure wave arrives is caused by the forward shove that the main accelerated mass exerts on the ice ahead of it, and the resulting preliminary basal cavitation causes the drop in water pressure shortly before the pressure wave arrives. The mini-surge wave propagation is controlled by the propagation of the water-pressure wave in the basal water-conduit system. The propagation characteristics result from a longitudinal gradient (up-glacier increase) in hydraulic conductivity of the basal water system in response to the up-glacier increase of the basal water pressure in the minisurge wave. The mini-surge waves are initiated in a succession of areas situated generally progressively up-glacier during the course of the summer season. In these areas, presumably, melt water that has accumulated in subglacial
\end{abstract}

*Contribution No. 3734, Division of Geological and Planetary Sciences, California Institute of Technology, Pasadena, California 91125, U.S.A.
(?) reservoirs is released suddenly into the basal water system immediately below, generating a pressure rise that propagates down-stream from there. Relationships of the mini-surges to the main surge are seen in the role of high basal water pressure in causing the rapid glacier motion in both phenomena, in the pulse-propagation features of both, and in the high outflow turbidity associated with both. The mini-surges of Variegated Glacier have a strong resemblance to movement and uplift events observed in Unteraargletscher and Findelengletscher, Switzerland. This bears on the question whether the mini-surges are a particular characteristic of surge-type glaciers prior to surge.

\section{INTRODUCTION}

The role of internal or basal water pressure in the flow of glaciers is receiving much attention in theoretical terms and is widely recognized as important, but has been difficult to demonstrate observationally. We report here the observation of dramatic glacier-flow events that are the direct and unambiguous result of basal water pressure affecting flow. These events, which we call "mini-surges", are significant both because they constitute a flow phenomenon exhibiting a large effect of water pressure on flow, and also because they appear to have been premonitory to a glacier surge, and thus may provide clues to the mechanism of the surge.

The observations were made on Variegated Glacier, St. Elias Range, Alaska (lat. $60^{\circ} 00^{\prime} \mathrm{N}$., long. $139^{\circ} 10^{\prime} \mathrm{W}$.), in 1978-80. This glacier surged in 1982-83. The process of build-up towards the surge was monitored by W.D. Harrison, C.F. Raymond, and colleagues (see Raymond and others, unpublished; and previous reports referenced therein). General characteristics of the glacier have been described by Bindschadler and others (1977). A preliminary report on the 1982-83 surge has been given by Kamb and others (1985).

The report by Kamb and others (1985) concludes that the immediate cause of the rapid glacier flow in the surge was high basal water pressure, just as in the mini-surges described here. As manifestations of the effects of basal water pressure on flow, the mini-surges are in fact clearer and more unambiguous than the surge itself.

Observation and interpretation of the mini-surges of Variegated Glacier are given in five separate papers. The present paper deals with water-pressure measurements in relation to short-term measurements of glacier motion. A second paper (Raymond and Malone, 1986) deals with strain-meter and seismicity measurements, and a third paper (Humphrey and others, 1986) deals with observations of water flow and turbidity in the terminal outlet stream. A fourth paper (in preparation by Kamb and others) will interpret the observations in terms of a theoretical model of mini-surge propagation, and a fifth paper will concentrate on observations in 1981 related to initiation of the minisurges. 


\section{FIELD SITUATION AND METHODS OF OBSERVATION}

Of the approximately $20 \mathrm{~km}$ length of Variegated Glacier, the present study addresses a $7 \mathrm{~km}$ segment as shown in Figure 1. The longitudinal positions of points on the glacier are given in terms of a curvilinear coordinate shown by the longitudinal kilometer scale in Figure 1, and are expressed in "Km". Most of the observational effort was concentrated in the interval from $\mathrm{Km} 6$, near the entry point of the main lateral tributary, down to $\mathrm{Km} 8.5$. The ice thickness of the trunk glacier was $350-420 \mathrm{~m}$, the surface slope $4-8^{\circ}$, and the flow velocity in 1978-80 ranged from $25 \mathrm{~cm} / \mathrm{d}$ near $\mathrm{Km} 10$ to $65 \mathrm{~cm} / \mathrm{d}$ near $\mathrm{Km} 4$ (Raymond and others, unpublished).

The surface motion of the glacier was followed on a daily basis in 1979 at station $\mathrm{F}+6(\mathrm{Km} \mathrm{6.5})$, and on a daily to hourly basis in 1980 at the array of stations shown in Figure 1. At $\mathrm{F}+6$ in 1979 and at $\mathrm{T}$ (near the margin at $\mathrm{km} 6.5$ ) in 1980, the motion was measured by theodolite resection with use of bedrock reference points $\mathrm{MC}$, NW, and SE (Fig. 1). At most other stations in 1980, the motion was measured by electronic distance meter (EDM) ranging. The EDM instruments (one Sokkisha Red 1A and one HewlettPackard 3600) were operated at the stations marked with a solid square in Figure 1. The motion of these stations was obtained from EDM shots to bedrock reference points 14, MC, NW, and SE (Fig. 1). Shots from the EDM stations to the target stations marked with a solid circle in Figure 1 gave the line-of-sight component of relative motion of the target stations, which can be converted to absolute motions for these stations with the help of assumptions as to the azimuths of the motions. EDM readings were corrected to a standard temperature and pressure $\left(15^{\circ} \mathrm{C}, 760 \mathrm{~mm} \mathrm{Hg}\right)$ with use of temperature and pressure readings made at each EDM station; geometrical corrections for instrument and target height and for re-setting of instrument and target stakes were made in the usual way. The vertical position of station $\mathrm{T}$ in 1980 was measured by means of theodolite vertical angles to bedrock point NW. Theodolite shots in the semi-darkness near midnight were made possible by floodlight illumination of the targets at $\mathrm{NW}$ and $\mathrm{SE}$, under radio control from $T$.

To observe basal sliding and basal water pressures, a bore hole was drilled through the glacier at site $\mathrm{F}+6$
(Km 6.5) in 1978, several bore holes were drilled at or near this site and one at site $\mathrm{VK}(\mathrm{Km} \mathrm{8.8})$ in 1979, and several were drilled at site $\mathrm{C}(\mathrm{Km} 6.4)$ and one at $\mathrm{vw}(\mathrm{Km} \mathrm{8.1)}$ in 1980. The bore-hole sites are shown with open circles in Figure 1. Except for the 1978 hole, which was drilled electrothermally, all bore holes were drilled by the hot-water drilling method with equipment designed and built by $\mathrm{Mr}$ P. Taylor, Seattle, Washington. Most of the holes were completed by cable-tool drilling and sand-pump bailing, to make sure that the bottom of the glacier was reached (see Engelhardt and others, 1978, p. 473). Individual bore holes are designated by the letter $\mathbf{v}$ followed by a second letter assigned in the order in which the holes were drilled. All bore holes were located approximately on the glacier center line.

Bore-hole water levels were measured with pressure transducers lowered into the holes, following the method of Hodge (1976); in 1978, a sounding float was used. The transducer signals were recorded continuously on strip-chart recorders; in 1980, the records included hourly time marks. The pressure transducers used in 1979 and 1980 had ranges of 100 p.s.i. and 300 p.s.i., respectively, corresponding to water-level ranges of about 65 and $200 \mathrm{~m}$. With the shorter range, it was occasionally necessary to reset the transducer positions by raising or lowering them in the bore holes in order to follow the fluctuating water levels and, when this was not accomplished, periods of record were lost by being off-scale.

\section{MINI-SURGES}

Approximately 1 day periods of dramatically accelerated motion in Variegated Glacier occurred repeatedly during June and July in 1978-81. These movement events, called by us "mini-surges", were first detected in 1978 and were fully demonstrated in 1979 by daily motion surveys and by strain-meter measurements (Raymond and Malone, 1986). Hourly motions measured in 1980 give a detailed picture of the movement that takes place in the mini-surges. Further mini-surge observations were made in 1981, particularly in the mini-surge "source area" above $\mathrm{Km} \mathrm{6}$; these observations will for the most part be reported in a subsequent paper.

The mini-surges that occurred in 1979 and 1980 are shown in Figures 2 and 3 in terms of the daily motions measured at $\mathrm{Km} 6.5$ (stations $\mathrm{F}+6$ and $\mathrm{T}$; Fig. 1). The

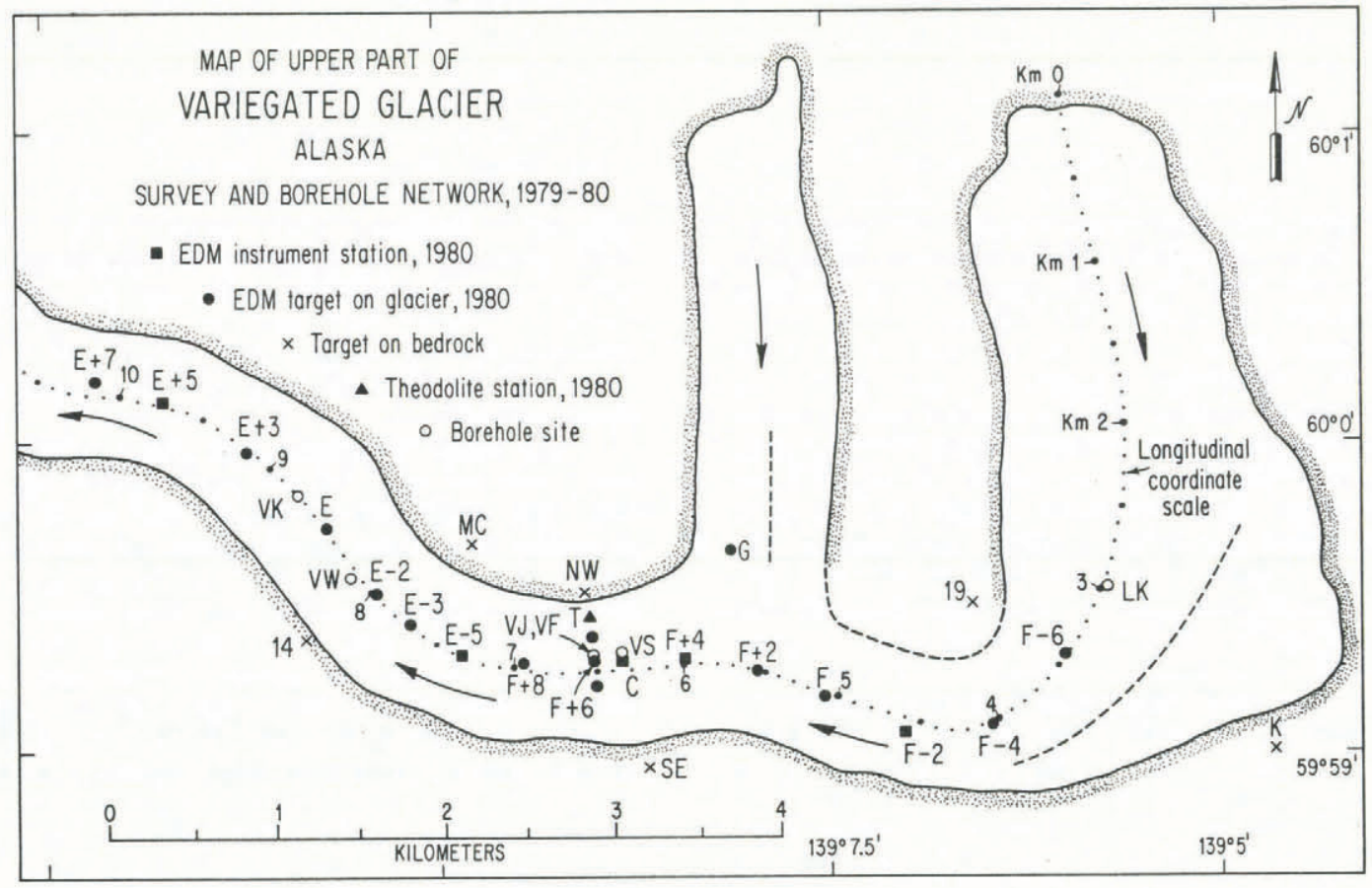

Fig. 1. Map of upper part of Variegated Glacier, Alaska, showing bore-hole siles and network of instrument and target stations on the glacier and on bedrock for field seasons 1979 and 1980 . Longitudinal coordinate scale is shown along glacier center line, with $\mathrm{km}$ marks numbered (from $\mathrm{KmO}$ at head of glacier). Dashed lines indicate flow boundaries within continuously ice-covered areas. 


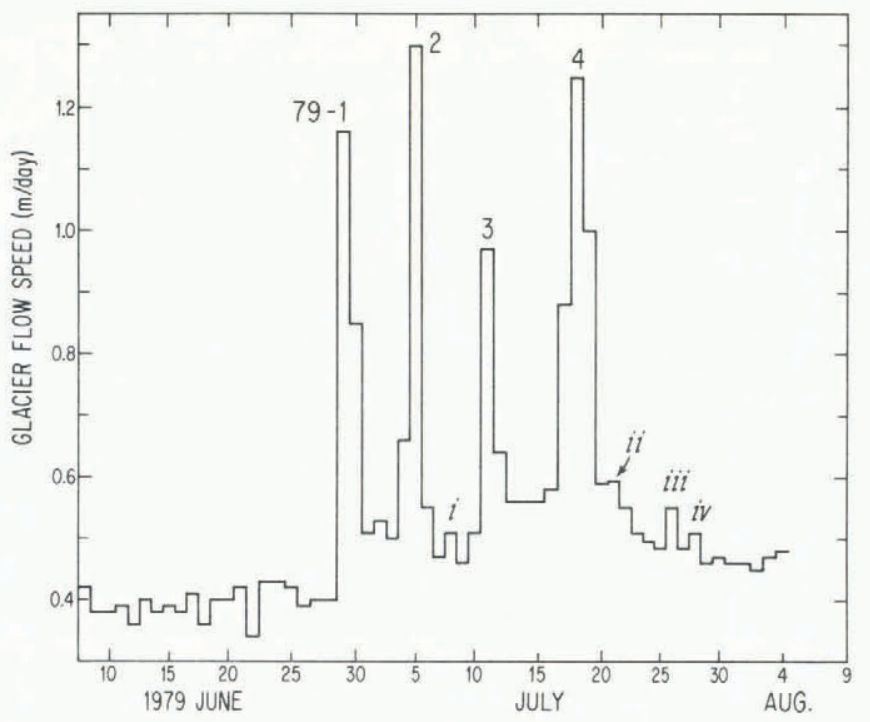

Fig. 2. Glacier-flow speed (daily values) at Km 6.5 (station $\mathrm{F}+6$ ) in 1979. Abscissa scale is in days; each tick is at $00.00 \mathrm{~h}$ on the date indicated. The mini-surge events are identified by number. Each value plotted is the average horizontal component of mean surface velocity from near noon one day to near noon the next day, and is shown in the figure as a constant value over the noon-to-noon interval involved. Flow-enhancement events that are not mini-surges are marked with lower-case roman numerals.

first mini-surge of the summer season (29 June 1979; 16 June 1980) marked the change from a winter-time flow velocity of about $38 \mathrm{~cm} / \mathrm{d}$ to summer-time "normal" (non-mini-surge) velocities of about $50-55 \mathrm{~cm} / \mathrm{d}$. Superimposed on the summer-time "normal" are high peaks of daily motion in the range $80-140 \mathrm{~cm} / \mathrm{d}$; these are the mini-surges, and they are accompanied by the several characteristics described below, and by Raymond and Malone (1986) and Humphrey and others (1986). Records of seismicity and of daily motion from automatic camera photographs (Harrison and others, 1986) indicate that outside the time windows of Figures 2 and 3 there was one additional mini-surge in 1980, on 16 August, and none in 1979. We think that three or four mini-surges occurred in 1978; the evidence in Figures 2 and 3, and from the automatic cameras and seismometers, shows that four mini-surges occurred in 1979, six or seven in 1980, and eight in 1981; the figure for 1981 is based on detailed observations to be reported in a later paper. Table I gives a chronology of the known or suspected mini-surges that occurred in 1978-81. Individual mini-surges are designated by year and number as in Table $I$ and in Figures 2 and 3.

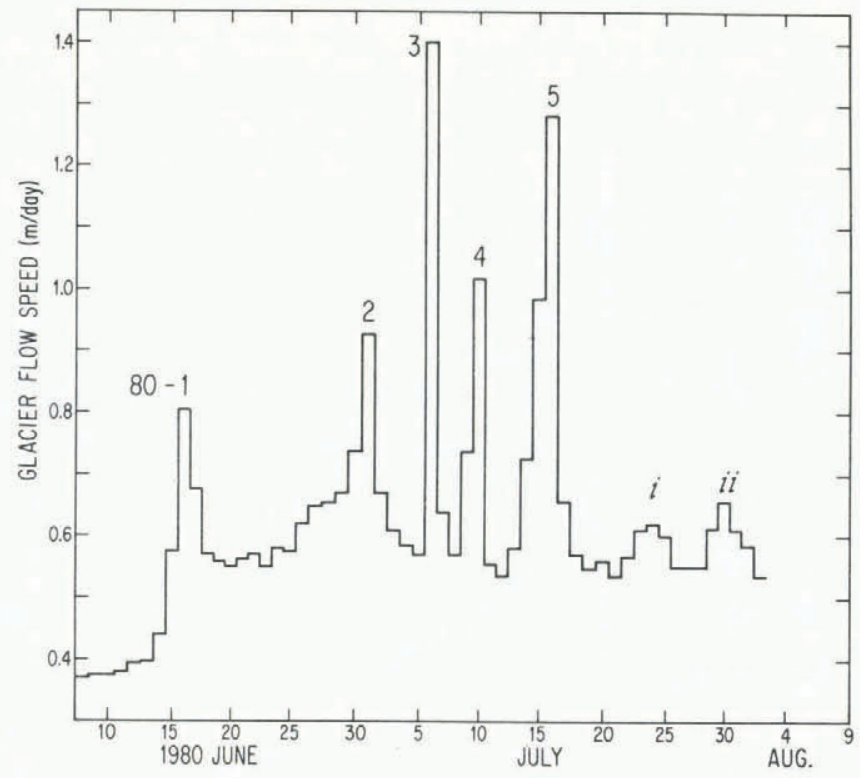

Fig. 3. Glacier-flow speed (daily values) at Km 6.5 (station T) in 1980. Same conventions as in Figure 2. Mini-surge events are marked by number; two non-mini-surge events are also identified ( $i$ and $i i$ ).

Characteristic features of the mini-surges are typified by the two examples given in Figures 4 and 5, for events $80-4$ and $80-5$, the two mini-surges for which we have the most nearly complete data coverage. These figures show the time variation, over a period of $3 \mathrm{~d}$ that includes the minisurge, of glacier-flow velocity, elevation of the glacier surface, and water level in two bore holes, one near where the flow velocity and surface elevation were measured, and a second one about $2 \mathrm{~km}$ down-stream. The features seen in these figures are discussed in detail below.

\section{GLACIER-FLOW BEHAVIOR IN MINI-SURGES}

For mini-surge events $80-1,80-3,80-4$, and $80-5$ the detailed variations of flow speed with time at points near $\mathrm{Km} 6.5,7.3$, and 8.5 are shown on an expanded time-scale in Figures 6-10. Each speed value in Figures $2-10$ is plotted as a horizontal line spanning the time interval over which it was measured, between successive surveys. Each value is an average over the time interval plotted. The actual flow speed is doubtless a continuous, reasonably smooth function of time, which can be inferred from the data in the figures by drawing a smooth curve in such a way as to satisfy the constraints provided by the average speed values (horizontal lines), with due regard for the

TABLE I. CHRONOLOGY OF MINI-SURGE EVENTS

\begin{tabular}{|c|c|c|c|c|c|c|c|c|c|c|}
\hline \multicolumn{2}{|c|}{1978} & \multicolumn{3}{|c|}{1979} & \multicolumn{3}{|c|}{1980} & \multicolumn{3}{|c|}{1981} \\
\hline Event $\neq$ & Date & Event & Date & s.a.* & Event & Date & s.a.* & Event & Date & s.a. ${ }^{*}$ \\
\hline $78-1 a$ & 1 Jul. & $79-1$ & 29 Jun. & m6 & $80-1$ & 15 Jun. & $\mathrm{m} 6$ & $81-1$ & 2 Jun. & $\mathrm{m}$ \\
\hline $1 \mathrm{~b}$ & 2 Jul. & & & & 2 & 30 Jun. & $t$ & 2 & 20 Jun. & $\mathrm{t}$ \\
\hline $2 a$ & 10 Jul. & 2 & 4-5 Jul. & & 3 & 6 Jul. & $\mathrm{t}$ & 3 & 26 Jun. & $t$ \\
\hline $2 \mathrm{~b}$ & 12 Jul. & 3 & 11 Aug. & $\mathrm{m} 4$ & 4 & 9 Jul. & $\mathrm{m} 4$ & 4 & 2 Jul. & $\mathrm{m}$ \\
\hline $3 a$ & $21 \mathrm{Jul}$. & & & & - & (14 Jul.) & $(t)^{\dagger}$ & 5 & 13 Jul. & $\mathrm{t}$ \\
\hline $3 b$ & 23 Jul. & 4 & 17 Aug. & $\mathrm{m} 4$ & 5 & $15 \mathrm{Jul}$. & $\mathrm{m} 3$ & 6 & $14 \mathrm{Jul}$. & $\mathrm{m} 3$ \\
\hline 4 & 31 Jul. & & & & 6 & 15 Aug. & & $\begin{array}{l}7 \\
8\end{array}$ & $\begin{array}{c}7 \text { Aug. } \\
27 \text { Aug. }\end{array}$ & $\begin{array}{l}\mathrm{m} \\
\mathrm{m}\end{array}$ \\
\hline
\end{tabular}

\footnotetext{
* Source area: $\mathrm{m}=$ main glacier, $\mathrm{t}=$ tributary, $\mathrm{m} 3=$ main glacier in general area of $\mathrm{Km} 3$, etc.

${ }^{\dagger}$ Speed-up in tributary, not distinguishable in main glacier from event 80-5.

‡ Events listed are water-level peaks; inference of mini-surge occurrence is hypothetical except for event 78-3a; paired events $(a, b)$ are not necessarily separate mini-surges.
} 


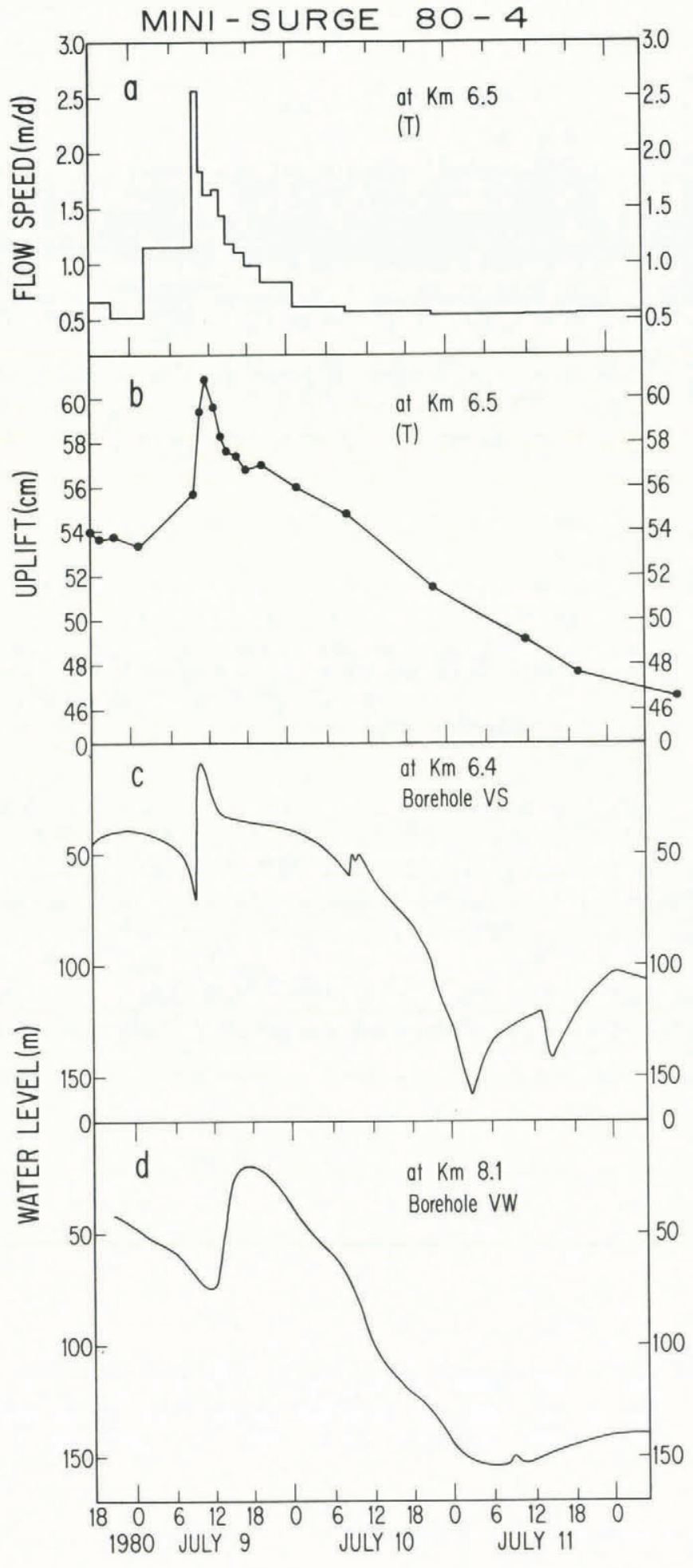

Fig. 4. For mini-surge 80-4, the figure shows the time variation of (a) glacier-flow speed at $\mathrm{Km} 6.5$, (b) uplift of the glacier surface at Km6.5 (station $\mathrm{T}$ ), (c) water level in bore hole vs at $\mathrm{Km} 6.4$, and (d) water level in bore hole vw at $\mathrm{Km} \quad 8.1$, over a $3 d$ period embracing 9-11 July 1980. For full explanation see text, sections $4-6$.

probable error of these values, and taking into consideration the fact that individual surveying errors displace adjacent speed values in opposite directions. From tests of the precision of the EDM and theodolite measurements, it is estimated that the probable error in the speed values is approximately $0.1 \mathrm{~m} / \mathrm{d}$ divided by the measurement time interval in hours.* In most of the flow-speed plots, the pattern of smooth variation is evident without the need to draw a smooth curve explicitly. In cases where the measure-

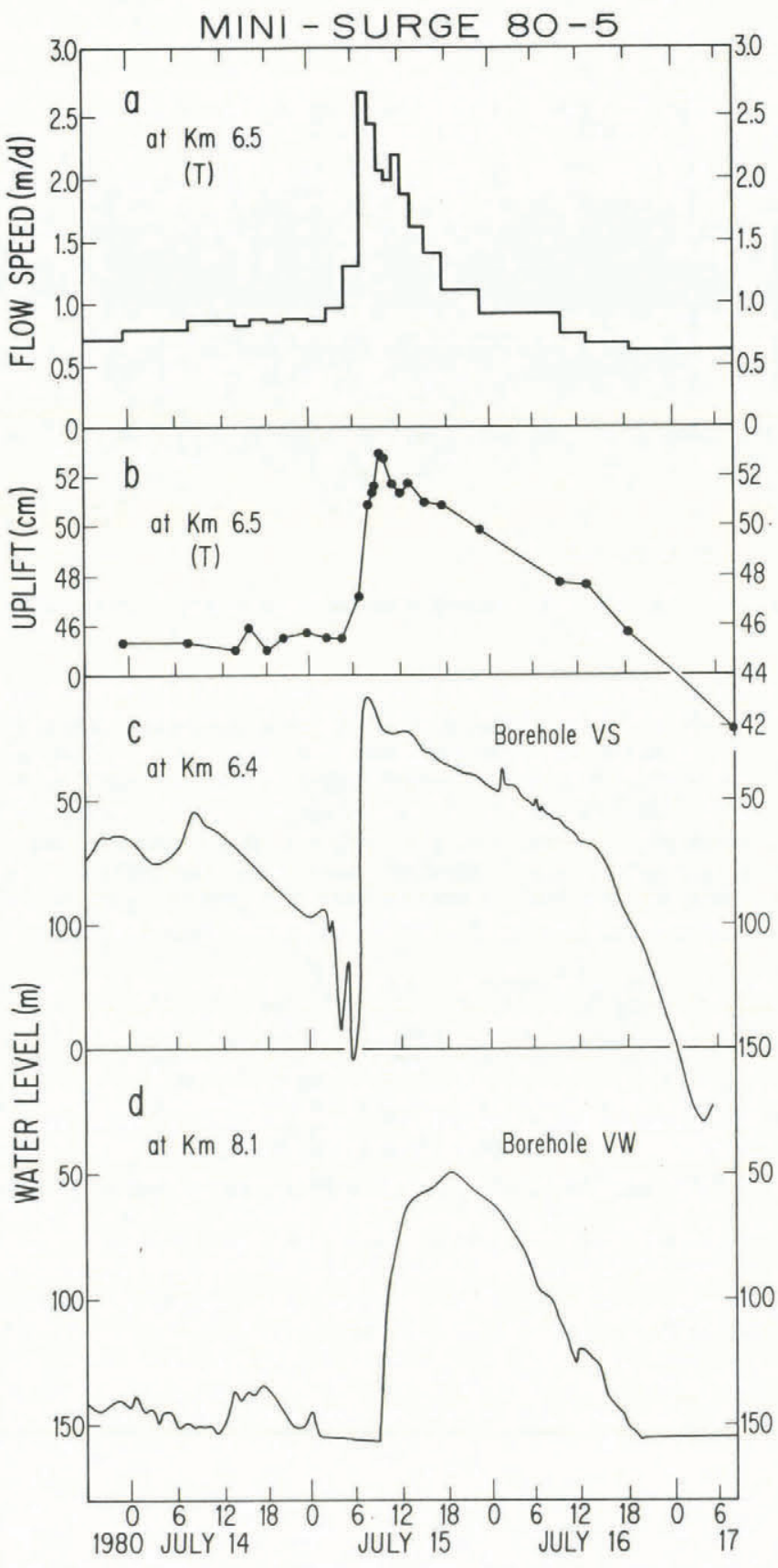

Fig. 5. For mini-surge 80-5, the figure shows the time variation of (a) glacier-flow speed at $\mathrm{Km} 6.5$, (b) uplift of the glacier surface at Km6.5 (station T), (c) water

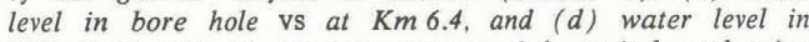
bore hole $\mathrm{vw}$ at $\mathrm{Km} 8.1$, over a $3 d$ period embracing 14-16 July 1980.

ments do not provide close enough constraint, a dotted line in the figures shows the curve that we infer or surmise, taking into consideration constraints outside the time windows of the figures.

The detailed pattern of flow speed vs time in mini-surges is shown by the individual data plots in Figures

* This is based on a standard error of $3 \mathrm{~mm}$ for individual EDM shots and for individual theodolite shots from station $\mathrm{T}$ to $\mathrm{NW}$ at a distance of $180 \mathrm{~m}$. If, in addition, a standard error of $2 \mathrm{~min}$ is assumed for the measurement of the time interval $\Delta t$, then the estimated probable error in velocity $v$ is $\sigma_{v}=0.1\left(\sqrt{1+0.2 v^{2}}\right) / \Delta t$ where $\Delta t$ is in hours and $v$ and $\sigma_{v}$ are in $\mathrm{m} / \mathrm{d}$. An additional error, due to errors in the correction for air temperature and pressure, is difficult to assess but is probably small, because it is found that the correction makes little change in the $v$ values. 
MINI-SURGE $80-1$

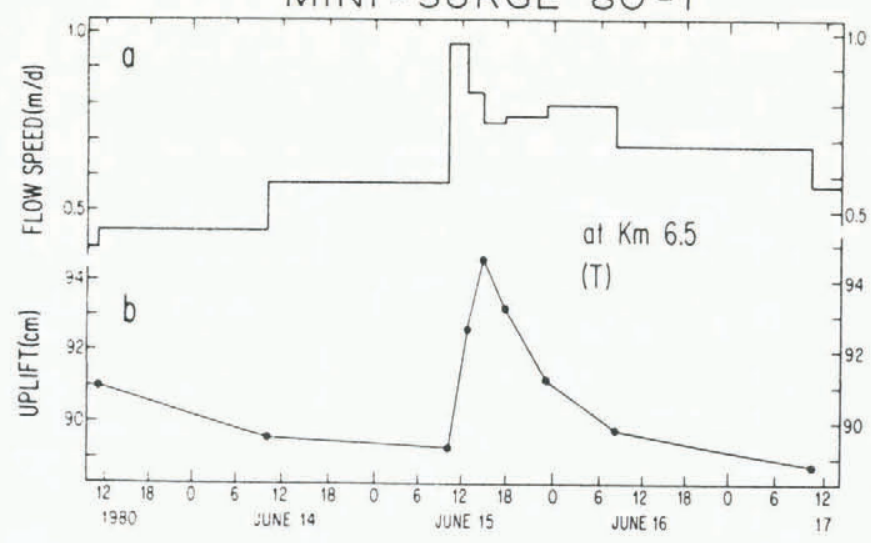

Fig. 6. For mini-surge 80-1, the figure shows (a) glacier-flow speed and (b) uplift of the glacier surface at Km 6.5 (station T) as a function of time over 13-17 June 1980. Abscissa scale is in hours.

$4 a, 5 a, 6 a, 7 c, d, f, 8 c, e$, and 9c, d, e, which give directly measured velocity vs time for mini-surges observed near $\mathrm{Km} 6.5$ and 7.3 , where they are best characterized by our measurements. The pattern is an asymmetric pulse of extra movement, consisting of a rapid increase from "normal" summer-time speeds of about $55 \mathrm{~cm} / \mathrm{d}$ to a peak speed of some $100-300 \mathrm{~cm} / \mathrm{d}$, followed by a slower decline back to "normal", the pulse lasting about a day. Peak speeds greater than about $200 \mathrm{~cm} / \mathrm{d}$, which were observed in minisurges $80-3,80-4$, and $80-5$, are in the range of speeds later measured in the same reach when the glacier was in the early stages of its main surge, in 1982 (Kamb and others, 1985). The onset of each mini-surge consists of a modest preliminary speed-up over a period of 3 or $4 \mathrm{~h}$, followed by a rapid increase to the peak in about an hour or less. Although the velocity generally decreases gradually after the main peak, some of the velocity curves show a shoulder or weak secondary peak a few hours later. Most of the velocity decrease occurs in the first $12 \mathrm{~h}$ after the main peak. However, "normal" velocity is not usually reached until $24-36 \mathrm{~h}$ after the peak. The initial rise appears to be somewhat less abrupt at $\mathrm{Km} 7.3$ than at $\mathrm{Km} 6.5$, and the asymmetry of the peak less pronounced, though still evident. These are aspects of attenuation of the velocity pulse downglacier, which becomes more pronounced in comparing the subdued velocity peaks at $\mathrm{Km} 8.5$ (Figs $7 \mathrm{~g}, 8 \mathrm{~g}$, and $9 \mathrm{f}$ )* with the peaks at $\mathrm{Km} 7.3$ (Figs $7 \mathrm{f}, 8 \mathrm{e}$, and $9 \mathrm{e}$ ).

*The velocity data in Figures $7 \mathrm{~g}, 8 \mathrm{~g}$, and $9 \mathrm{f}$ were obtained by combination of EDM measurements from station E-5 to bedrock station 14 and from E-5 to E-2. The combination (which is obtained by concatenation of the two data sets with linear interpolation in time between EDM distance values, because the distances to 14 and E-2 were not shot at the same time) leads to more widely fluctuating velocity values than are obtained from direct shots to bedrock. To damp these fluctuations, it is necessary to take average values over longer time intervals, of order $2 \mathrm{~h}$, as done in Figures $7 \mathrm{~g}, 8 \mathrm{~g}$, and $9 \mathrm{f}$. There is also a possibility that, due to inaccuracies in the geometrical assumptions made in combining the two sets of EDM measurements, the velocity curve at $\mathrm{Km} 8.4(\mathrm{E}-2)$ will to some extent be "contaminated" by the velocity pulse at $\mathrm{Km} 7.3(\mathrm{E}-5)$. Some suggestion of this is seen in Figure $8 \mathrm{~g}$.

at $\mathrm{Km} 6.5$ (station T). (e) Uplift of the glacier surface (relative to an arbitrary local datum for vertical elevation) at station $\mathrm{T}(\mathrm{Km} 6.5)$; measured points are connected by straight lines; estimated standard error of uplift values is $0.2 \mathrm{~cm}$. (f) Glacier-flow speed at $\mathrm{Km} 7.3$ (station E-5). (g) Flow speed at Km 8.5 (station E). (h) Seismicity at $K m$ 8.6; note scale change at 200 counts/h. (a) and (h) are from Raymond and Malone (1986).
MINI-SURGE $80-3$
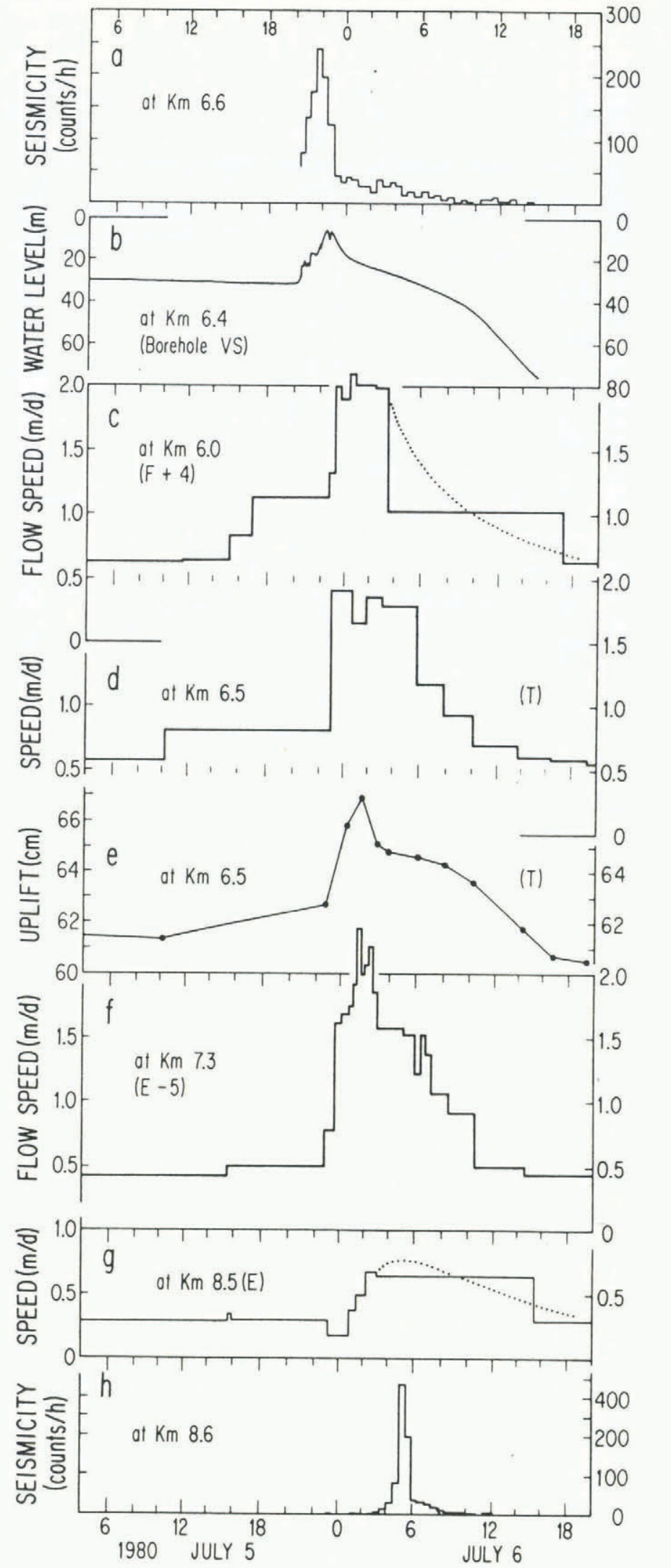

Fig. 7. Detailed information for mini-surge $80-3$, as a function of time from $04.00 \mathrm{~h}$ on 5 July to $20.00 \mathrm{~h}$ on 6 July 1980. (a) Seismicity at Km 6.6; counting-rate values are averages over half-hour intervals, each count being $a$ seismic event above the detection threshold. (b) Water level (depth below glacier surface) in bore hole vs at $\mathrm{Km} 6.4$. (c) Glacier-flow speed (horizontal component) at Km 6.0 (station F+4); speed values are averages over the time intervals spanned by the horizontal lines plotted; dotted line shows surmised variation (see text). (d) Flow speed 
MINI-SURGE $80-4$

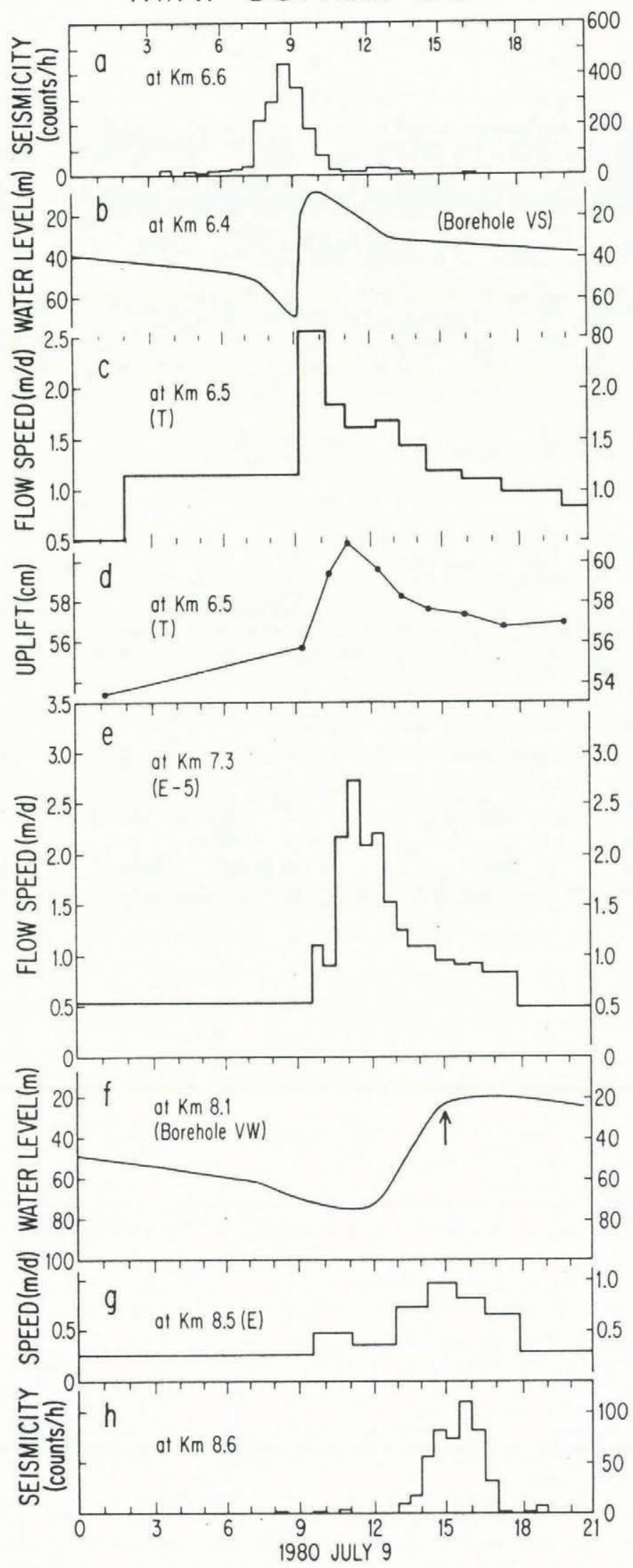

Fig. 8. Detailed information for mini-surge $80-4$, as a function of time on 9 July 1980. Abscissa scale is in hours; 0 is $00.00 \mathrm{~h}$. (a) Seismicity at $\mathrm{Km} \mathrm{6.6.} \mathrm{(b)} \mathrm{Water}$ level (depth below glacier surface) in bore hole vs at $\mathrm{Km}$ 6.4. (c) Glacier-flow speed at Km 6.5 (station T). (d) Uplift of glacier surface (relative to arbitrary local datum) at station $\mathrm{T}(\mathrm{Km} 6.5)$. (e) Glacier-flow speed at $\mathrm{Km} 7.3$ (station E-5). (f) Water level in bore hole $\mathrm{vw}$ at $\mathrm{Km} 8.1$; arrow indicates shoulder at top of water-level rise. ( $g$ ) Flow speed at Km8.5 (station E). (h) Seismicity at $\mathrm{Km}$ 8.6. (a) and ( $h$ ) are from Raymond and Malone (1986). Further details as in caption to Figure 7.
MINI-SURGE $80-5$

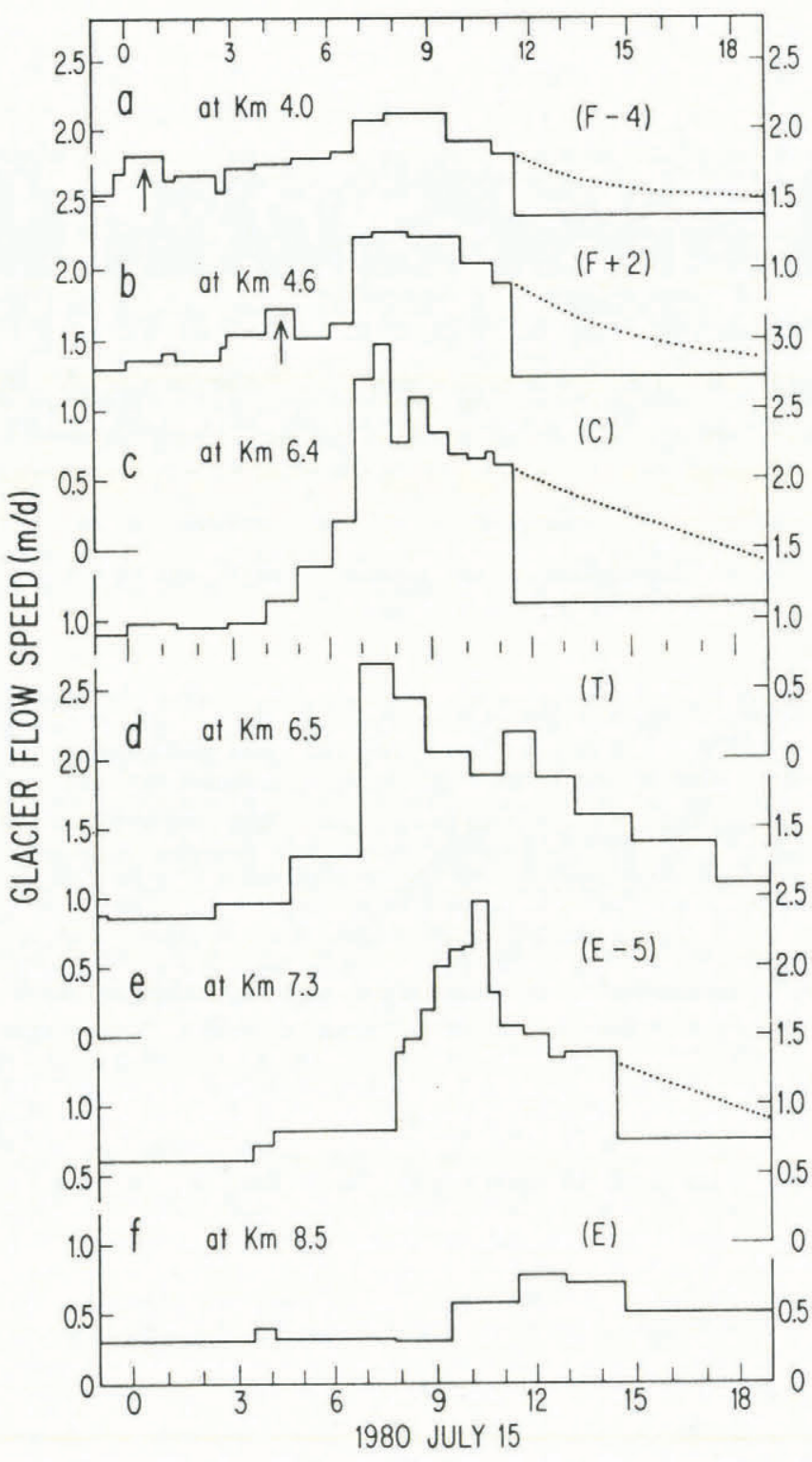

Fig. 9. Detailed glacier-flow data for mini-surge 80-5. Flow speed (average values over the time intervals plotted as horizontal lines) as a function of time (h) on 15 July 1980 is shown for five stations, at the longitudinal coordinates indicated (station designations in parentheses). Dotted lines indicate surmised course of flow curves. consistent with data constraints. Arrows in (a) and (b) mark the initial, down-glacier-propagating peak.

The mini-surge flow-velocity peak moves as a wave down the glacier, at a speed of about $300 \mathrm{~m} / \mathrm{h}$. Propagation of the flow wave in events $80-3$ and $80-4$ is seen by comparing the times of the velocity peaks at $\mathrm{Km} 6.5,7.3$, and 8.5 in Figures $7 \mathrm{c}, \mathrm{f}, \mathrm{h}$, and $8 \mathrm{c}, \mathrm{e}, \mathrm{g}$. The best display of flow-wave propagation is in Figure 9, which shows the flow wave of event $80-5$ at six points in the reach $\mathrm{Km} 4.5$ to 8.5 , with the best time resolution achieved in our measurements. The flow pulse is most strongly developed between $\mathrm{Km} 6.5$ and 7.3. Attenuation in amplitude is evident at $\mathrm{Km} 8.5$. EDM shots from station $\mathrm{E}+5$, at $\mathrm{Km} 9.6$, showed that the pulse died out between $\mathrm{Km} 9.6$ and 10.0 .

In the upper part of the reach, at $\mathrm{Km} 4.0$ and 5.5 , the flow wave in event $80-5$ (Fig. 9a, b) is building up, and is distinctly different in form from the pulse at $\mathrm{Km} \mathrm{6.4}$. There is a modest initial peak (marked with an arrow in Figure $9 \mathrm{a}, \mathrm{b})$, which propagates down-glacier at a speed of about $350 \mathrm{~m} / \mathrm{h}$. This is followed by a larger peak that occurs 
MINI-SURGE $80-5$

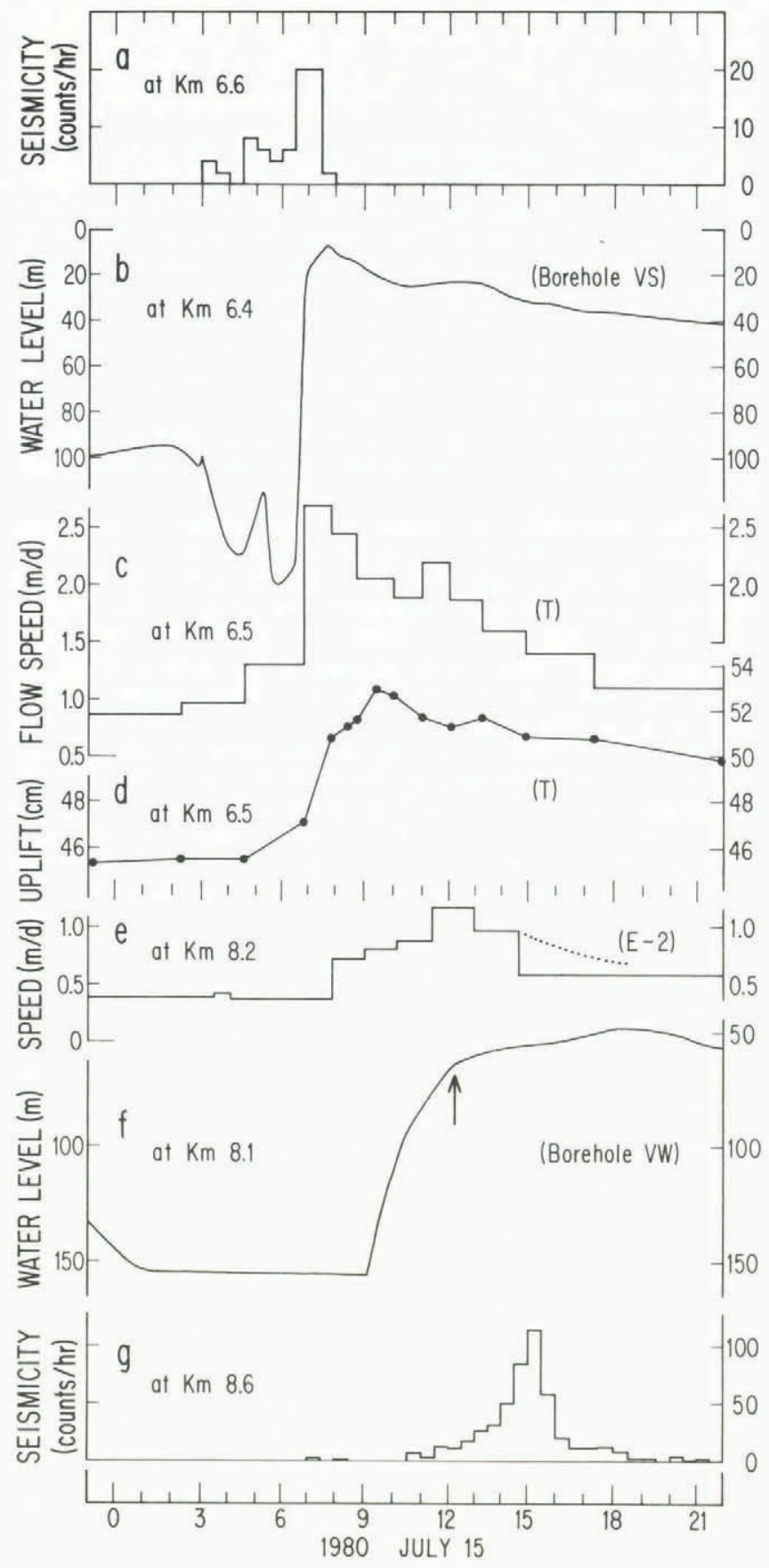

Fig. 10. Detailed information for mini-surge 80-5, as a function of time (h) on 15 July 1980. (a) Seismicity at Km6.6 (tilt of seismometer caused counting rates to be anomalously low). (b) Water level (depth below glacier surface) in bore hole vs at $\mathrm{Km}$ 6.4. (c) Glacier-flow speed at $\mathrm{Km} 6.5$ (station T). (d) Uplift of glacier surface (relative to arbitrary local datum) at station $\mathrm{T}(\mathrm{Km} 6.5)$. (e) Flow speed at Km 8.0 (station E-2). (f) Seismicity at $\mathrm{Km}$ 8.6. Data in (a) and ( $g$ ) are from Raymond and Malone (1986, fig. 5).

synchronously with the peak at $\mathrm{Km} 6.4 .^{*}$ In event 80-3, similarly, the flow speed-up at $\mathrm{Km} 6.0$ and 6.5 appears to occur synchronously (Fig. 7c, d).

*Since the data in Figure $9 \mathrm{a}, \mathrm{b}$ were obtained by combination of EDM shots from station $c$ to station 14 and from $\mathrm{C}$ to $\mathrm{F}+2$ and to $\mathrm{F}-4$, it is possible that the velocity peak synchronous with the peak at $\mathrm{km} 6.4$ is to some extent caused by "contamination" from the motion of station c, as discussed in the previous footnote. However, the peak is so large that it is probably not grossly falsified in this way.
Data from the transverse profile of four markers at Km 6.5 (including points $F+6$ and $T$; Fig. 1) show that the mini-surges involve a speed-up across the whole profile, slightly greater (by $0.1-0.3 \mathrm{~m} / \mathrm{d}$ ) at the center $(F+6)$ than near the margin ( $\mathrm{T}$ ).

Some mini-surges are preceded by a gradual premonitory flow build-up over a period of $1-5 \mathrm{~d}$ before onset of the actual event. Proven examples of premonitory build-up occurred before event 79-2 (1 d), 80-1 (at least $2 \mathrm{~d}), 80-2 \quad(5 \mathrm{~d})$, and $80-5$ (3 d). These premonitory increases can be seen in Figures 2 and 3. (However, caution in interpreting the data in this respect is necessary because if a mini-surge occurs near mid-day, enhanced daily motion will be found on two successive days, since daily surveys are usually made near mid-day.) When a premonitory increase is not observed, such as before events $79-1$ and $80-3$ as monitored at $\mathrm{Km} 6.5$ (Figs 2 and 3), this may only indicate that the observing station was not close enough to the "build-up area" to detect the build-up. Thus, in event $80-3$, a premonitory build-up was detected in EDM shots from station $F+4$ to station $G$, in the tributary, but it was not recognizable at station $\mathrm{F}+6$ (Fig. 3).

\section{VERTICAL MOTIONS ACCOMPANYING MINI-SURGES}

Figure 11 shows the elevation of a reference mark embedded in the glacier at station $\mathrm{T}(\mathrm{Km} \mathrm{6.5}$; Fig. 1) as a function of time and horizontal displacement during June and July 1980. The general trend is a decrease in elevation at an average rate of about $2 \mathrm{~cm} / \mathrm{d}$, which represents the overall downward component of flow of the glacier. Superimposed on this trend are four sharp uplift peaks, which precisely accompany mini-surge events $80-1,80-3,80-4$, and $80-5$. Each uplift peak is preceded by a 1-3 d period of premonitory uplift, in which the elevation remains approximately constant, representing effectively a progressive uplift relative to the normal downward trend. Such a period was also observed prior to event $80-2$ (Fig. 11) but, because the hourly measurements were not continued during the event itself, an uplift peak, if it occurred, was missed. The height of the uplift peaks increases progressively through the sequence of mini-surges: $80-1,6 \mathrm{~cm} ; 80-3,7.5 \mathrm{~cm} ; 80-4$, $9 \mathrm{~cm} ; 80-5,11 \mathrm{~cm}$.

The detailed patterns of uplift accompanying events $80-1,80-3,80-4$, and $80-5$ at station $T$ are shown in Figures $4 b, 5 b, 6 b, 7 e, 8 d$, and $10 d$, where they can be examined alongside corresponding flow-velocity curves. In

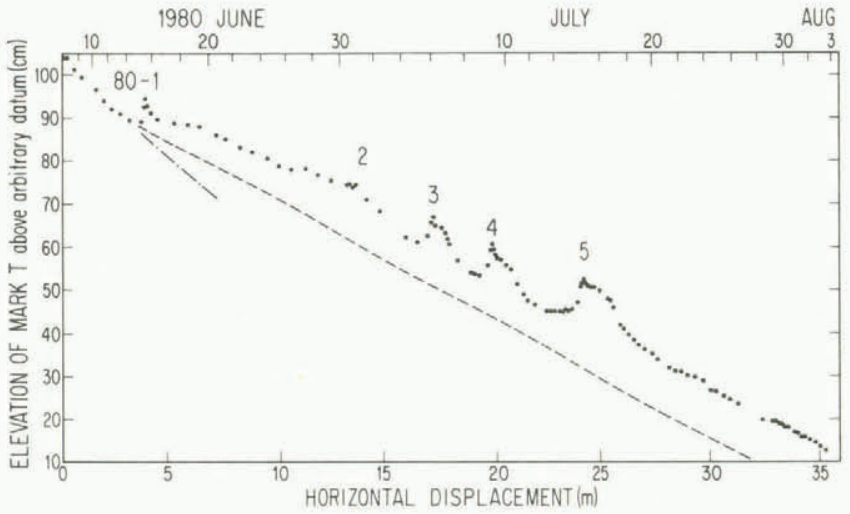

Fig. 11. Elevation of reference mark imbedded in glacier surface at station $\mathrm{T}(\mathrm{Km} 6.5)$ in 1980 , plotted as a function of longitudinal position relative to an arbitrary origin at the initial position. Elevation (in $\mathrm{cm}$ ) is given relative to an arbitrary local datum. Mini-surge events are numbered. At the top is a time-scale, which is non-uniform because of the varying flow velocity; ticks, every $2 d$, are at $00.00 \mathrm{~h}$ on the dates indicated. The dash-dot line is an extrapolation of the trend of elevation versus horizontal displacement established prior to 14 June. The dashed line is plotted from the 14 June elevation onward at the slope seen during times distant from mini-surges; it represents an estimated reference line relative to which uplift due to basal cavitation in the "summer-time" flow regime may be assessed (see text). 
addition to the premonitory relative uplift already mentioned, there appears generally to be some absolute uplift just prior to the main velocity increase. The maximum uplift rate coincides with the maximum flow velocity. The peak uplift always occurs about $2 \mathrm{~h}$ after the peak flow velocity. After reaching its peak, the uplift drops relatively rapidly for $1-3 \mathrm{~h}$, and more slowly thereafter.

Event $80-1$ was followed by continued uplift relative to the normal downward trend, until 19 June. Over this period the total effective uplift relative to the dashed line in Figure 11 was $7 \mathrm{~cm}$. A further uplift of about $3 \mathrm{~cm}$ occurred during 25-27 June, at the time when the premonitory flow-velocity increase prior to event $80-2$ began. The dashed line in Figure 11 is drawn to follow the general trend of the elevation of mark $T$ during the mini-surge period; its slope $(0.027)$ is less steep than the trend established prior to the mini-surge period (slope 0.046, dash-dot line in Figure 11).

\section{BASAL WATER PRESSURE}

Every mini-surge is accompanied by a dramatic rise in the basal water pressure to extremely high levels. Bore-hole water-level data from field seasons 1978 through 1980 are given in Figures 12-14. Similarly to what has been observed in other glaciers (Hodge, 1976; Engelhardt and others, 1978, p. 493 et seq.), the typical behavior of the water level in each bore hole is an initial nearly constant level in the range $15-40 \mathrm{~m}$, followed by a drop to deeper levels and by subsequent large fluctuations. We interpret the drop as indicating establishment of hydraulic connection between the bore hole and the basal water system of the glacier; the water level then provides a measure of the water pressure in this system. In some bore holes, the first drop is to an intermediate depth at which the water level becomes again nearly constant for a time, before a further drop and commencement of large fluctuations (Figs 12 and 14a). We interpret such a first drop as due to establishment of connection with an intraglacial water conduit; it sometimes occurs in the course of drilling.

Many of the water-level fluctuations shown in Figures 12-14 are more or less diurnal in period and range over a vertical interval of a few tens of meters. Superimposed upon and dominating such fluctuations are events in which the water level rises rapidly to a depth of only $35 \mathrm{~m}$ to as little as $10 \mathrm{~m}$ below the glacier surface.* These dominating water-level peaks coincide one for one with the mini-surge events, which are identified with numbers in Figures 12-14.

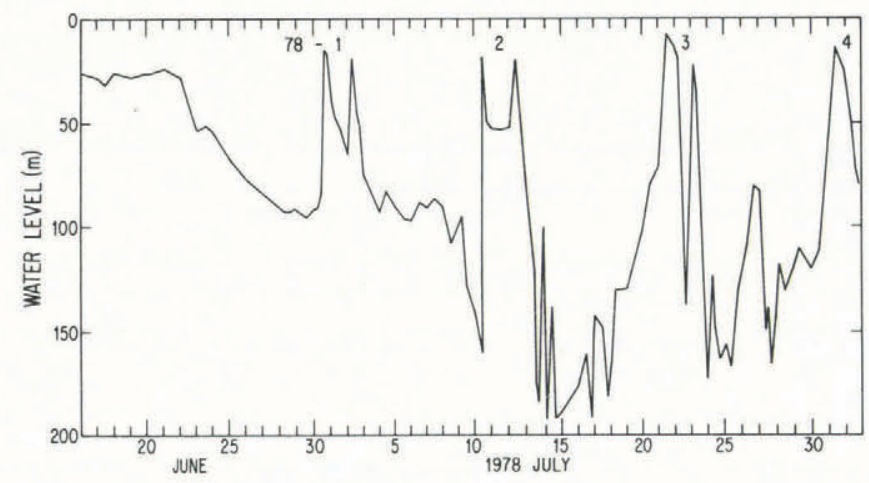

Fig. 12. Water level in bore hole VA at $\mathrm{Km} 6.5$, as a function of time in 1978. Abscissa scale is in days; each tick is at $00.00 \mathrm{~h}$ on the date indicated. Water level is given as depth below the glacier surface. Water-level peaks are numbered. Peak 79-3 coincides with a known mini-surge; the other peaks are surmised to correspond with mini-surges.

*The extremely high peak water level at bore hole vJ in event $79-4$, which is shown in Figure $13 \mathrm{c}$ as reaching a depth of only $1 \mathrm{~m}$ below the glacier surface, is perhaps questionable because the surface there was underlain by about $7 \mathrm{~m}$ of permeable firn, but it is indicated unambiguously by the pressure-transducer record.
The designation of mini-surges for 1978 in Figure 12 and Table I is mostly hypothetical, because a complete set of daily motion measurements was not made in 1978; however, event 78-3 was established by daily motion measurements over the period 17-31 July, which showed a motion pulse of $84 \mathrm{~cm} / \mathrm{d}$ on $20-21$ July.

Figure 14a indicates that event $80-2$ occurred before bore hole vs had established hydraulic communication with the basal water system as judged by the criteria described above, and yet a water-level peak coinciding with this event was recorded. Evidently, the high basal water pressure that accompanied the event was able to open up temporary communication with the bore hole but this was closed off again when the water pressure later dropped. In event 80-3, the water-level behavior started off in the same way, but after the event the communication between the bore hole and the basal water system remained open, and the water level dropped about $60 \mathrm{~m}$ below the prior, unconnected level.

The bore-hole water-level rise associated with each mini-surge is caused by injection of basal water into the bore hole at the bottom. This is shown by the fact that the bore-hole water becomes extremely turbid from bottom to top, as observed by bore hole TV and by a bore-hole turbidity meter. Also, after a mini-surge, glacial flour is found deposited on the pressure transducer cables within $20 \mathrm{~m}$ or so of the surface.

Water-level peaks reaching within $36 \mathrm{~m}$ of the glacier surface in well connected bore holes at $\mathrm{Km} 6.5$ are accompanied by a flow speed-up of mini-surge type (section 4). A water level $36 \mathrm{~m}$ below the surface is near the "flotation level", that is, the level at which the basal water pressure equals the ice-overburden pressure, which, for ice

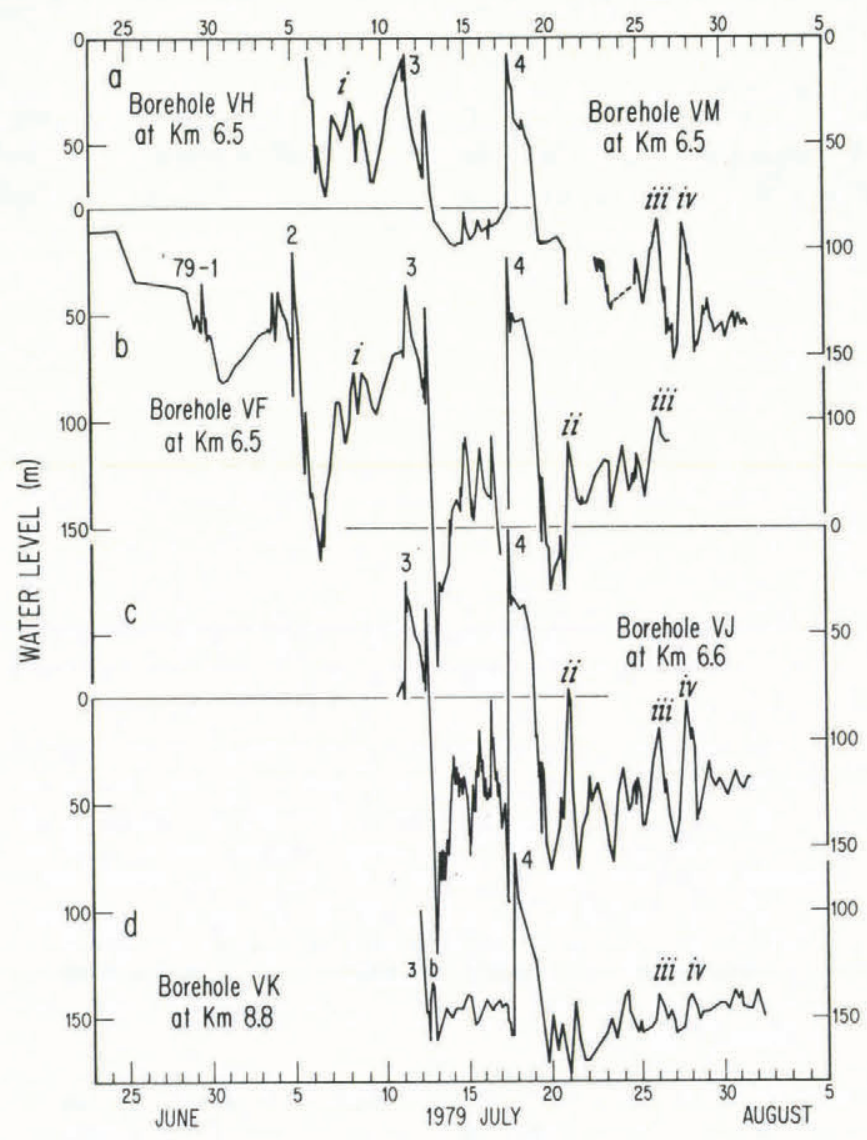

Fig. 13. Bore-hole water levels as a function of time in 1979. Abscissa scale is in days, with tick at $00.00 \mathrm{~h}$ on each date indicated. Water level is given as depth below the glacier surface. The mini-surges are numbered. Water-level peaks labeled with lower-case roman numerals correspond to movement events that are not mini-surges, identified in Figure 2. (a) Bore hole $\mathrm{VH}$, and, later, VM, at $\mathrm{Km}$ 6.5. (b) Bore hole VF, at $\mathrm{Km}$ 6.5. (c) Bore hole VJ, at $\mathrm{Km}$ 6.6. (d) Bore hole vK, at $\mathrm{Km} 8.8$. 


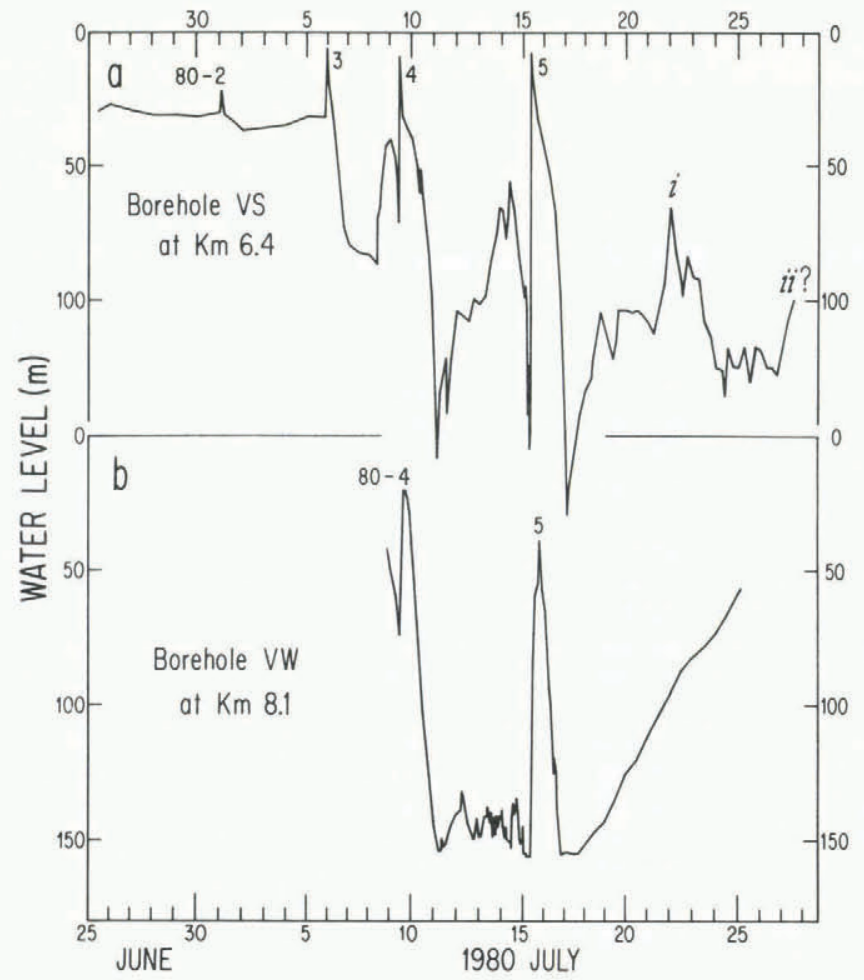

Fig. 14. Bore-hole water levels as a function of time in 1980; (a) at Km 6.4 (bore hole vs), and (b) at Km8.1 (bore hole vw). Abscissa scale is in days; ticks are at $00.00 \mathrm{~h}$ on the dates indicated. Water level is given as depth below the glacier surface. The mini-surges are numbered. The peak labeled $i$ corresponds to the non-mini-surge flow-enhancement event so marked in Figure 3.

about $375 \mathrm{~m}$ thick (as was the case at $\mathrm{Km} 6.5$ in 1979-80), is a level about $38 \mathrm{~m}$ below the surface. The highest waterlevel peaks not accompanied by mini-surges are those at $38-40 \mathrm{~m}$ below surface on 3-4 and 12 July 1979 (Fig. 13a) and on 8 July 1980 (Fig. 14a).* Down-glacier, at Km 8-9, the height of water-level peaks associated with mini-surges was somewhat lower than at $\mathrm{Km}$ 6.5: the water level in event $79-4$ peaked at $73 \mathrm{~m}$ below surface in bore hole vK (Fig. 13d), and that in $80-5$ at $48 \mathrm{~m}$ below surface in bore hole vw (Fig. 14b). These levels are somewhat below flotation level at the down-glacier bore-hole sites, where the ice was about $410 \mathrm{~m}$ thick.

After each mini-surge event, except sometimes the last in the summer sequences observed in 1978-80, the water level drops to a new low for the summer. The successive low-water levels in each of the summer sequences are listed in Table II. The deepest water level recorded was $215 \mathrm{~m}$, in bore hole VF, where the total ice thickness was $380 \mathrm{~m}$.

The detailed course of the water-level fluctuations accompanying mini-surges in 1979 is shown in Figures 15-17, and of those in 1980 in Figures 7,8 , and 10. The curves are dashed where drawn interpretively over time periods when pressure-transducer data are missing because of instrumental malfunction or being off-scale. Although no two water-level curves are identical, the curves have a

*In bore holes less well connected to the basal water system, the water levels stand higher, hence higher peaks unaccompanied by mini-surges may be observed in such holes. For example, in bore hole $\mathrm{vH}$ the water level followed a course of variation similar to that in bore hole $\mathrm{VF}, 10 \mathrm{~m}$ away, and in $\mathrm{vJ}, 100 \mathrm{~m}$ away, but was always higher, by an amount that varied from 15 to $100 \mathrm{~m}$ (Fig. $13 \mathrm{a}, \mathrm{b}, \mathrm{c})$. The water-level peaks at $29-35 \mathrm{~m}$ below surface in bore hole $\mathrm{VH}$ on 7,8 , and 12 July correspond to peaks of lower water level in the other bore holes and were not accompanied by mini-surges. number of recurring and consistent features, as follows. The overall pattern is asymmetric: a rapid rise followed by a slower decline, similar to the velocity curves. Just prior to the water-level rise, there is often a drop of a few to as much as $50 \mathrm{~m}$, lasting one to several hours (Figs $4 \mathrm{c}, 5 \mathrm{c}, 8 \mathrm{~b}$, $10 \mathrm{~b}, 15 \mathrm{~b}, \mathrm{~d}, 16 \mathrm{~b}, \mathrm{~d}, 17 \mathrm{~b}, \mathrm{~d}, \mathrm{e})$. In instances where this
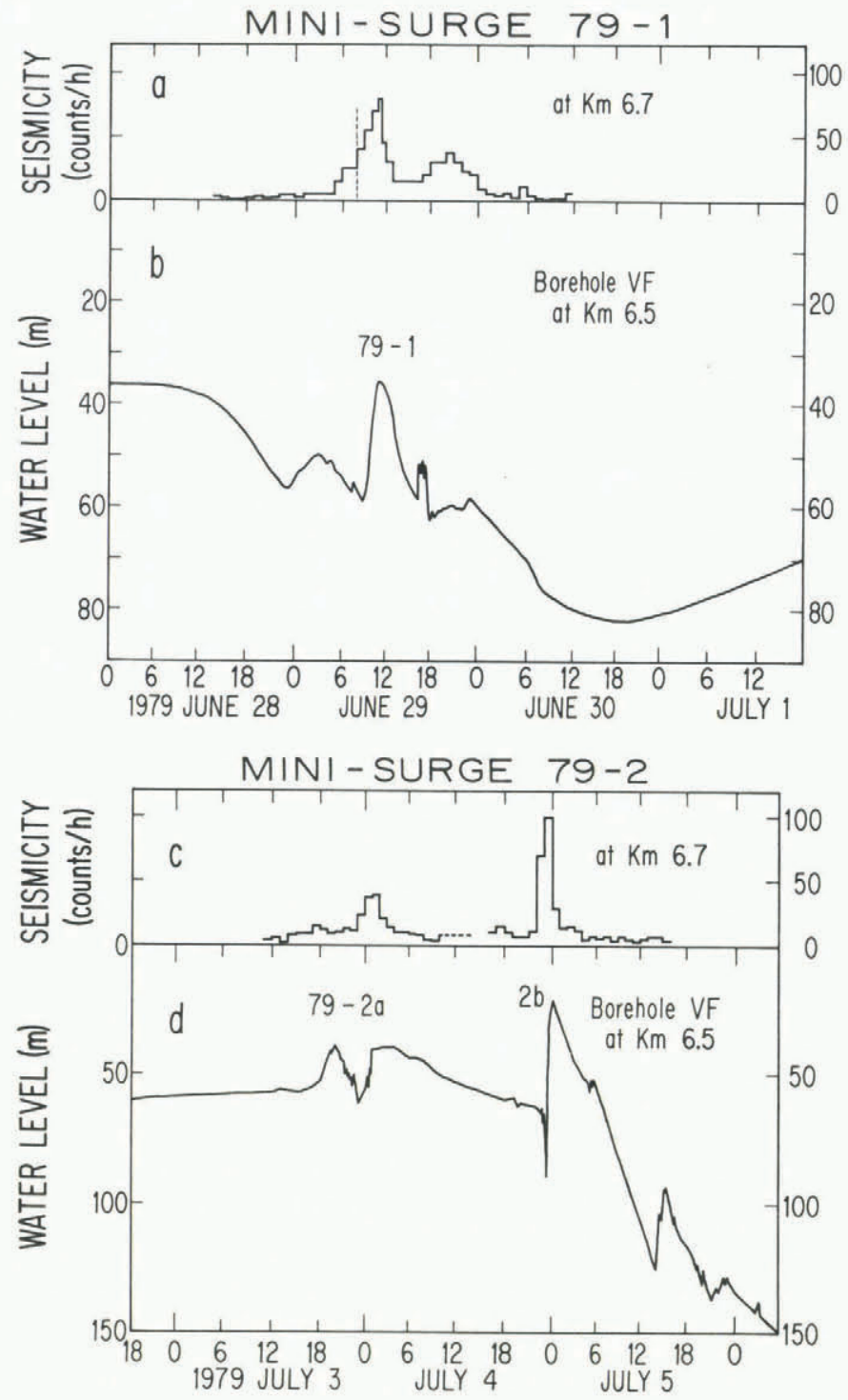

Fig. 15. Bore-hole water levels and seismicity data for mini-surges 79-1 and 79-2. (a) 79-1, seismicity at Km 6.7; (b) 79-1, water level in bore hole VF at Km6.5. (c) 79-2, seismicity at $\mathrm{Km} 6.7$; (d) 79-2, water level in bore hole VF at Km6.5. Abscissa scales are in hours. Data in (a) and (c) are from Raymond and Malone (1986), with additions as follows. In (a) over the period 29 June $03.00-20.00 \mathrm{~h}$, and in (c) over 3 July 11.00-4 July $14.00 \mathrm{~h}$, the seismic activity was counted by us from the original seismograms. In (a) the event cut-off amplitude was taken twice as great prior to $08.00 \mathrm{~h}$ as afterwards, to take into account a reduction in seismometer gain of $6 \mathrm{db}$ that was made at that time (marked by a vertical dashed line); this eliminated the apparent peak in seismicity at $07.00-08.00 \mathrm{~h}$ in the plot of Raymond and Malone (1986, fig. 3); the latter plot is the source of the data in (a) outside the interval 29 June 02.00-10.00, except that counting rates prior to $03.00 \mathrm{~h}$ have been halved to agree approximately with our counting rates where the two data sets overlap. Our counting rates in (a) were also adjusted somewhat to fit qualitative estimates of relative seismic activity from overall inspection of the seismogram, so as to improve the representation of the peak near 29 June $11.00 \mathrm{~h}$ and to counteract the difficulty of making numerically reliable event counts in the cluttered record. 
TABLE II. SUCCESSION OF BORE-HOLE WATER LEVELS (HIGH AND SUBSEQUENT LOIV) ASSOCIATED WITH MINI-SURGES IN 1978-80

\begin{tabular}{|c|c|c|c|c|c|c|}
\hline \multicolumn{7}{|c|}{ Water level* } \\
\hline \multirow[t]{2}{*}{ Year } & Date & Event & $\begin{array}{c}\text { Event } \\
\text { high }\end{array}$ & $\begin{array}{c}\text { Subsequent } \\
\text { low }\end{array}$ & $\begin{array}{c}\text { Date of } \\
\text { low }\end{array}$ & Bore holc \\
\hline & & & $\mathrm{m}$ & $\mathrm{m}$ & & \\
\hline \multirow[t]{4}{*}{1978} & - & - & - & 94 & 29 Jun. & VA \\
\hline & $1 \mathrm{Jul}$. & $78-1$ & 15 & 159 & $10 \mathrm{Jul}$. & VA \\
\hline & $11 \mathrm{Jul}$. & 2 & 18 & 192 & $14 \mathrm{Jul}$. & VA \\
\hline & 21 Jul. & 3 & 8 & 173 & $23 \mathrm{Jul}$. & VA \\
\hline \multirow[t]{5}{*}{1979} & - & - & - & 57 & 28 Jun. & VF \\
\hline & 29 Jun. & $79-1$ & 35 & 82 & 1 Jul. & $\mathrm{VF}$ \\
\hline & 4 Jul. & $2 \mathrm{~b}$ & 22 & 166 & 6 Jul. & $\mathrm{VF}$ \\
\hline & 11 Jul. & $3 a$ & 36 & 215 & $13 \mathrm{Jul}$. & VF \\
\hline & 17 Jul. & 4 & 8 & 186 & 21 Jul. & vH \\
\hline \multirow[t]{5}{*}{1980} & - & - & - & 30 & 29 Jun. & vs \\
\hline & 30 Jun. & $80-2$ & 22 & 37 & 2 Jul. & vs \\
\hline & 5 Jul. & 3 & 6 & 86 & $8 \mathrm{Jul}$. & vs \\
\hline & 9 Jul. & 4 & 9 & 158 & 11 Jul. & vs \\
\hline & 15 Jul. & 5 & 8 & 179 & 17 Jul. & vs \\
\hline
\end{tabular}

* Bore-hole water level expressed as depth below glacier surface, in meters.

drop is missing (Figs 4d, 7b, 10f, 17c), one can usually see indications that the bore-hole water level is either rather sluggish (Fig. 17c) or "blocked" in such a way that it cannot drop below a certain fixed level, as is the case prior to bore-hole connection (Fig. 7b) as previously discussed, or as would be the case if connection with the basal water system were not via the bottom of the bore hole but instead via a natural intraglacial passageway intercepted at the depth where the water level is "blocked" (Figure 4d exemplifies this type of behavior).

In bore holes near $\mathrm{Km} \mathrm{6.5,} \mathrm{the} \mathrm{water-level} \mathrm{rise} \mathrm{in} \mathrm{the}$ mini-surges is usually very abrupt, the main part of the rise occurring in a fraction of an hour. Down-glacier, the rise is more gradual (Figs $8 \mathrm{f}, 10 \mathrm{f}, 17 \mathrm{e}$ ). To within the time resolution of our velocity measurements, the abrupt waterlevel rise coincides exactly with the rapid speed-up in flow velocity (Figs 7b, c, d, 8b, c, 10b, c). ${ }^{*}$ The coincidence is less sharp down-glacier, where the water-level rise and the speed-up are more gradual (Figs $8 \mathrm{e}, \mathrm{f}, 10 \mathrm{e}, \mathrm{f}$ ).

At $\mathrm{Km} 6.5$, a peak in water level closely follows the abrupt rise; this peak is essentially coincident with the peak in flow velocity. In 1980 this is shown directly by the data in Figures 7-9, and in 1979 it is shown indirectly by the coincidence of the peaks in water level and seismicity (Figs 15-17), the latter being essentially coincident with the velocity peaks, as established in 1980 (section 7). After peaking, the water level falls relatively slowly, usually after a short initial period of more rapid fall (Figs 4c, 5c, 17d). Down-glacier, the water-level peak tends to be more diffuse and to come later than the velocity peak (Figs 8f, 10f, 16e, $17 \mathrm{e})$.

The water-level rise propagates as a wave down the glacier, essentially in step with the flow-velocity rise. The propagation is manifested by the delayed arrival of the water-level wave at bore holes down-glacier, relative to its arrival at $\mathrm{Km} 6.5$, as shown by comparing Figures $4 \mathrm{c}$ and

*In event 80-2, short-term velocity measurements at station T show the start of a sharp up-swing in velocity at $20.00-22.00 \mathrm{~h}$ on 30 June, shortly before the time $(23.00 \mathrm{~h})$ when the water level in bore hole vs begins the sharp rise to the peak near midnight ( $30 \mathrm{June}-1$ July) seen in Figure 14a. The short-term velocity measurements were not continued further, so the rest of the detail of the velocity peak in event $80-2$ was missed. $\mathrm{d}, 5 \mathrm{c}$ and $\mathrm{d}, 8 \mathrm{~b}$ and $\mathrm{f}, 10 \mathrm{~b}$ and $\mathrm{f}$, and $17 \mathrm{~b}$ and $\mathrm{e}$. These comparisons also show that the water-level rise is attenuated in height and abruptness as it propagates down-glacier from $\mathrm{Km} 6.5$.

Figures 4 and 5 show the complete course of the decline in water level subsequent to events $80-4$ and $80-5$, together with the associated decay in flow velocity and uplift. From comparing the curves in these figures, it appears that the uplift follows the variation of water pressure as a whole more closely than it does the variation in flow velocity, the velocity dropping off more rapidly than the water pressure and uplift.

The water-level records for events $79-2$ and $79-3$, in Figures $15 \mathrm{~d}$ and 16, show that in connection with each of these events there occurred two water-level peaks, about $1 \mathrm{~d}$ apart, each of which almost reached the level, $36 \mathrm{~m}$ below the surface, at which initiation of a mini-surge is found as discussed above. The two peaks in Figure 15d are labeled $2 \mathrm{a}$ and $2 \mathrm{~b}$, and the two in Figure 16 are labeled $3 \mathrm{a}$ and 3b. (Peak $2 a$ is actually itself a double peak.) Similar pairs of peaks occurred in 1978, as indicated by Figure 12, but there were no such occurrences in 1980. Daily motions in 1979 (Fig. 2) show that the flow velocity was somewhat enhanced on the days when peaks $2 a$ and $3 b$ occurred, but the enhancements could be considered to be simply premonitory or tailing motions associated with the minisurges that accompanied peaks $2 b$ and $3 a$ (events $79-2$ and 79-3). The lack of a seismicity peak at the time of waterlevel peak 3b (Fig. 16a) and also the lack of any strain anomaly at this time (Raymond and Malone, 1986, fig. 4) show that a separate mini-surge did not accompany that water-level peak. However, a weak but definite seismicity peak was associated with peak 2a (see Fig, 15c), and it is therefore possible that a separate, perhaps weak mini-surge occurred at that time (the strain meters were not working). (The definitely enhanced seismicity occurred only in connection with the second peak of the double water-level peak $2 \mathrm{a}$, which is curious, because the water level reached $40 \mathrm{~m}$ below surface in both peaks.) As shown in Figure $16 \mathrm{~d}$, water-level peak $3 \mathrm{~b}$ was much more attenuated downglacier than is typical for peaks associated with mini-surges.

Although water-level peaks deeper than $36 \mathrm{~m}$ below surface in well-connected bore holes at $\mathrm{Km} 6.5$ are not associated with mini-surges, as discussed above, it appears that the highest of such peaks of ten correlate with modest, non-mini-surge enhancements in flow velocity. Examples are 


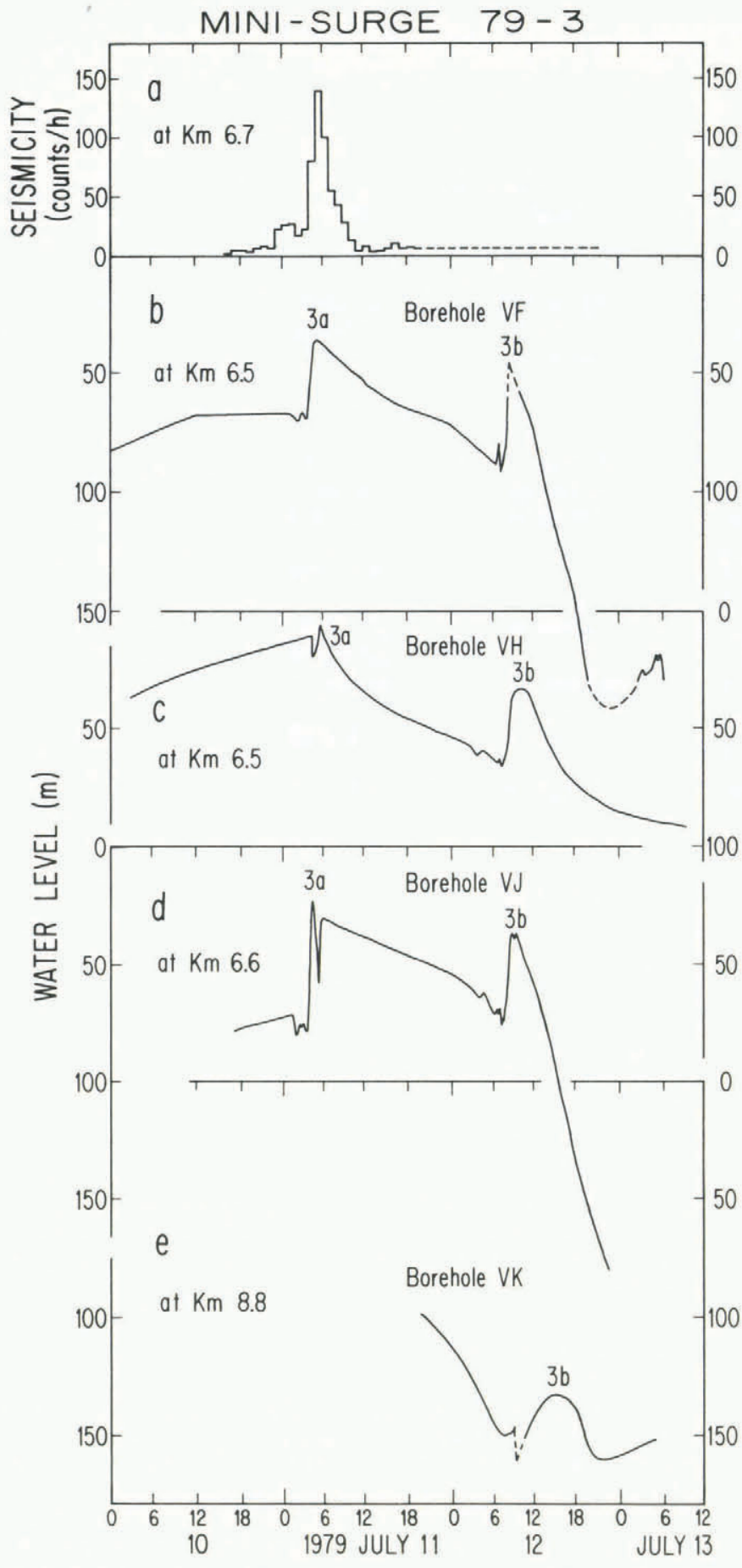

Fig. 16. Bore-hole water levels and seismicity data for mini-surge 79-3. (a) Seismicity at Km 6.7, from Raymond and Malone (1986); dashed part represents qualitative estimate from drum records. Water level (b) in bore hole VF at $\mathrm{Km} \mathrm{6.5;} \mathrm{(c)} \mathrm{in} \mathrm{bore} \mathrm{hole} \mathrm{VH}$ at $\mathrm{Km} \mathrm{6.5;} \mathrm{(d)} \mathrm{in} \mathrm{bore}$ hole vj at Km 6.6; (c) in bore hole vK at $\mathrm{Km} \mathrm{8.8.} \mathrm{Water}$ level is given as depth below glacier surface.

the small peaks in flow velocity labeled $i, i i$, iii, and $i v$ in Figure 2 and the larger, broader peaks labeled $i$ and $i i$ in Figure 3 ; the corresponding peaks in water level are indicated in Figures 13 and 14. Water-level peaks in Figure 13 for 14-16 July 1979 and in Figure 14 for $8-9$ and 13-14 July 1980 correspond to enhanced daily motions in Figures 2 and 3 , but these motions are not resolved from motion in the declining tail of an immediately preceding mini-surge or premonitory to an immediately following mini-surge.

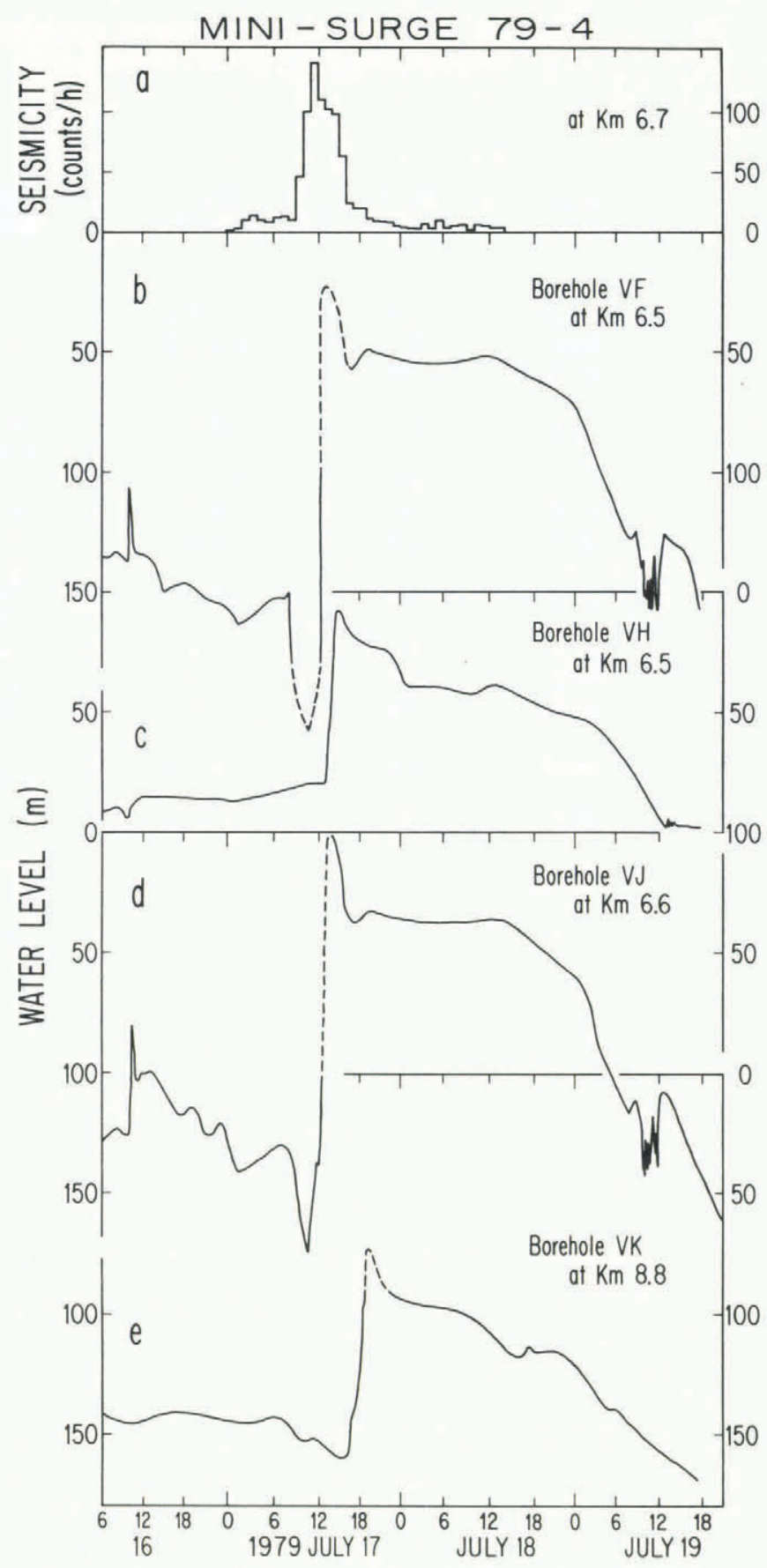

Fig. 17. Bore-hole water levels and seismicity data for mini-surge 79-4. (a) Seismicity at Km 6.7, from Raymond and Malone (1986). Water level (b) in bore hole $\mathrm{F}$ at $\mathrm{Km} 6.5$, (c) in bore hole vH at $\mathrm{Km} 6.5$, (d) in bore hole vJ at $\mathrm{Km}$ 6.6, and (e) in bore hole vK at $\mathrm{Km} 8.8$. Abscissa scale is in hours. Water level is given as depth below glacier surface, and is shown with a dashed curve schematically where pressure values were off-scale on the recorders.

\section{SEISMICITY}

Mini-surges are accompanied by vigorous, audible cracking and icequake activity, and by the formation of numerous new crevasses $(\sim 1 \mathrm{~mm}$ wide) cutting the glacier surface. Raymond and Malone (1986) described this seismicity, on the basis of seismometer measurements. Figures $7 \mathrm{a}, \mathrm{h}, 8 \mathrm{a}, \mathrm{h}, 10 \mathrm{a}, 15 \mathrm{a}, \mathrm{c}, 16 \mathrm{a}$, and $17 \mathrm{a}$ are plots of seismic activity, provided by C.F. Raymond and S. Malone. Comparison with the other plots in these figures establishes the relation between the seismicity and the flow velocity or 
TABLE III. MINI-SURGE PROPAGATION SPEEDS FOR FLOW-VELOCITY WAVE (FV), WATER-PRESSURE WAVE (WP), AND LONGITUDINAL STRAIN WAVE (LS)

\begin{tabular}{|c|c|c|c|c|c|}
\hline Event & $\begin{array}{c}\text { Wave } \\
\text { type }\end{array}$ & $\begin{array}{c}\text { Obs. } \\
\text { interval } \\
\mathrm{Km}\end{array}$ & $\begin{array}{c}\text { Obs. } \\
\text { stations }\end{array}+$ & $\begin{array}{l}\text { Propagation } \\
\text { Onset } \\
\mathrm{km} / \mathrm{h}\end{array}$ & $\begin{array}{l}\text { speed of } \\
\text { Peak } \\
\mathrm{km} / \mathrm{h}\end{array}$ \\
\hline $\begin{array}{l}79-3 b^{*} \\
79-4 \\
80-3\end{array}$ & $\begin{array}{l}\text { WP } \\
\text { WP } \\
\text { FV }\end{array}$ & $\begin{array}{l}6.6-8.8 \\
6.5-8.8 \\
6.5-7.3\end{array}$ & $\begin{array}{l}\mathrm{VJ} / \mathrm{VK} \\
\mathrm{VF} / \mathrm{VK} \\
\mathrm{T} / \mathrm{E}-5\end{array}$ & $\begin{array}{l}0.88 \pm 0.25^{*} \\
0.59 \pm 0.03 \\
0.69 \pm 0.40\end{array}$ & $\begin{array}{l}0.31 \pm 0.08 * \\
0.34 \pm 0.08 \\
0.39 \pm 0.10\end{array}$ \\
\hline $80-3$ & LS & $6.9-7.6$ & $\frac{F+6 / E-5}{E-5 / E-2}$ & - & $0.25 \pm 0.06$ \\
\hline $\begin{array}{l}80-3 \\
80-4 \\
80-4\end{array}$ & $\begin{array}{l}\text { FV } \\
\text { FV } \\
\text { WP }\end{array}$ & $\begin{array}{l}7.3-8.5 \\
6.5-7.3 \\
6.4-8.1\end{array}$ & $\begin{array}{l}\text { E-5/E } \\
\text { T/E-5 } \\
\text { VS/VW }\end{array}$ & $\begin{array}{l}0.50 \pm 0.23 \\
1.27 \pm 0.60 \\
0.60 \pm 0.35\end{array}$ & $\begin{array}{l}0.37 \pm 0.14 \\
0.42 \pm 0.13 \\
0.25 \pm 0.05\end{array}$ \\
\hline $80-4$ & LS & $6.9-7.6$ & $\frac{F+6 / E-5}{E-5 / E-2}$ & - & $0.29 \pm 0.06$ \\
\hline $\begin{array}{l}80-4 \\
80-5 \\
80-5\end{array}$ & $\begin{array}{l}\text { FV } \\
\text { FV } \\
\text { FV }\end{array}$ & $\begin{array}{l}7.3-8.5 \\
4.0-6.4 \\
6.4-7.3\end{array}$ & $\begin{array}{c}\mathrm{E}-5 / \mathrm{E} \\
\mathrm{F}-4 / \mathrm{C} \\
\mathrm{C}, \mathrm{T} / \mathrm{E}-5\end{array}$ & $\begin{array}{c}0.45 \pm 0.20 \\
- \\
\geqslant 0.74 \pm 0.35\end{array}$ & $\begin{array}{l}0.33 \pm 0.08 \\
0.35 \pm 0.06 \\
0.30 \pm 0.06\end{array}$ \\
\hline $80-5$ & LS & $6.4-7.5$ & $\frac{C / F+6}{E-5 / E-3}$ & - & $0.27 \pm 0.02$ \\
\hline $80-5$ & WP & $6.4-8.1$ & vs/vw & $0.68 \pm 0.05$ & $0.17 \pm 0.02$ \\
\hline $80-5$ & LS & $7.2-7.5$ & $\frac{F+8 / E-5}{E-5 / E-3}$ & - & $0.28 \pm 0.06$ \\
\hline $80-5$ & FV & $7.3-8.5$ & $E-5 / E$ & $\leqslant 0.70 \pm 0.45$ & $0.45 \pm 0.20$ \\
\hline
\end{tabular}

* Water-pressure wave not definitely associated with a mini-surge distinct from event 79-3a, for which no propagation speed is available.

† For wave type LS, the pairs of stations above and below the horizonatal bar indicate the longitudinal intervals whose strain records are compared to derive a propagation speed.

water pressure. The seismicity peak is approximately synchronous with the flow-velocity and water-pressure peaks. Near $\mathrm{Km} 6.5$, there appears to be a tendency for the seismicity peak to occur $0.5-1 \mathrm{~h}$ earlier than the flow-velocity or water-pressure peak:* this may indicate synchronism of the seismicity peak with the rapid increase in flow and pressure rather than with the peaks in these variables. Near

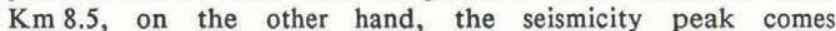
distinctly later than the rising part of the flow-velocity and water-pressure curves; correlation with peak flow velocity therefore seems more reasonable, but the poor time resolution of the velocity data here precludes a definitive conclusion. The seismicity peaks near $\mathrm{Km} 8.5$ are in some instances (Figs $7 \mathrm{~h}$ and $10 \mathrm{~g}$ ) remarkably sharp by comparison with the water-pressure and flow-velocity peaks there.

In 1980, seismicity in the uppermost part of the minisurge reach was monitored by a seismometer at $\mathrm{Km} \mathrm{3.3,}$ reporting by radiotelemetry link to our camp at $\mathrm{Km} \mathrm{6.4;}$ this system was kindly provided by $\operatorname{Dr} \mathrm{S}$. Malone. The system reported high seismicity at $\mathrm{Km} 3.2$ early in the development of events $80-4$ and $80-5$ but not in the earlier events. In event 80-5, high seismicity was reported at around midnight on 14-15 July, which is approximately the time of the initial peak in motion at $\mathrm{Km} 4.0$ (Fig. 9a; arrow). This supports the interpretation (in section 5) that the initial peak in motion is the manifestation at $\mathrm{Km} 4.0$ of the propagating mini-surge wave, which arrived about $7 \mathrm{~h}$

*In Figures $7 \mathrm{a}, \mathrm{d}$ and $8 \mathrm{a}, \mathrm{c}$ this effect is probably exaggerated, because flow-speed measurements of $1 \mathrm{~h}$ time resolution do not start definitely before the rapid speed-up, so that the measured peak in speed is probably somewhat late. If this is true in event $80-3$ at $\mathrm{Km} 6.5$ (Fig. 7d), then there appears to have been up-glacier propagation of the speed peak from $\mathrm{Km} 6.5$ to 6.0 (Fig. 7c). later at $\mathrm{Km} 6.4$. In event $80-4$, high seismicity at $\mathrm{Km} 3.2$ was reported $18 \mathrm{~h}$ before the onset of the mini-surge at $\mathrm{Km} 6.4$ but a detailed record of motion near $\mathrm{Km} 4$ is not available for comparison.

\section{WAVE-PROPAGATION SPEED}

Propagation speeds for the flow-velocity and waterpressure waves, over the various spatial intervals of observation for the data in Figures $7-10$ and 15-17, are listed in Table III with the wave-type designations "FV" and "WP" in column 2. Because the sharpness of the waves is attenuated below $\mathrm{Km} 6.5$, the leading edge or onset of the waves propagates faster than the peak there, and separate velocity values for onset and peak are therefore given in Table III, columns 5 and 6 . For the onset, we take the point in time at which the major, rapid increase in flow velocity or water pressure begins; this is usually better defined in the water-pressure records than in the flowvelocity data. At the time resolution of Figures $8 \mathrm{f}$ and $10 \mathrm{f}$, the water-pressure peaks from down-glacier bore hole vw at $\mathrm{Km} \mathrm{8.1}$ are broad and poorly defined, but at the scale of Figures $4 \mathrm{~d}$ and $5 \mathrm{~d}$ the peaks are clear and propagation speeds can be obtained; because the water-level peak lags behind the velocity peak down-glacier (as noted in section 6 ), the propagation speeds obtained for the water-level peak are lower than the speeds of the flow-velocity peak (Table III). Instead of the peak, a better representation of the arrival time of high water pressure down-glacier is given by the conspicuous shoulder in the water-level curve at the top of the main rise, marked with an arrow in Figures $8 \mathrm{f}$ and $10 \mathrm{f}$; because the shoulder comes at about the time of peak flow velocity (Figs $8 \mathrm{e}$ and 10e), propagation speeds based on arrival time of the shoulder agree approximately with speeds of the flow-velocity wave. The wide ranges of uncertainty indicated for the individual propagation velocities 
in Table III reflect the foregoing aspects of poor definition of onsets or peaks in the individual curves of flow velocity and water level. Table III also contains propagation speeds obtained from long-interval strain curves (section 9), listed with designation "Ls" in column 2.

With due regard for the scatter of values in Table III, we can say that the onset of the waves propagates at a speed of some 600 to perhaps $800 \mathrm{~m} / \mathrm{h}$, and the peak propagates at $250-400 \mathrm{~m} / \mathrm{h}$, there being roughly a difference of a factor of two between the two speeds. Although propagation-speed values for the water-pressure waves and flow-velocity waves in Table III are in general different, the differences do not imply that the two wave types propagate basically out of step or independently but rather reflect scatter stemming from the rather crude time resolution of the data, or, in the case of the water-level peak, the lagging discussed above.

The wave-propagation speeds obtained by Raymond and Malone (1986, table II) from strain-meter and seismicity data are of the same order of magnitude as the speeds obtained here for propagation of the flow-velocity and water-pressure peaks, but in detail there is not a good correspondence between the two sets of results, the speeds derived from the strain-meter and seismicity data being in many cases distinctly lower, as are, also, the speeds from long-interval strain curves (section 9). The lagging of the seismicity peak behind the water-level rise near $\mathrm{Km} 8-9$, noted in section 7 , causes propagation speeds obtained from seismicity to be relatively slow.

\section{LONG-INTERVAL STRAIN}

Changes in the measured distances between markers in the longitudinal array shown in Figure 1 give longitudinal strains averaged over the distance intervals between the markers; these are here called "long-interval strains" to distinguish them from the short-interval strains measured over $10 \mathrm{~m}$ intervals by Raymond and Malone (1986). Longinterval strain data over two intervals in the reach $\mathrm{Km} \mathrm{6.5-}$ 8.0 are given for events $80-3,80-4$, and $80-5$ in Figure 18 . In each plot, the magnitudes of the strain changes corresponding to the distance changes plotted are indicated by a strain scale-bar. Where measurement points are lacking, a strain curve is drawn as an interpretive interpolation. Although the measurements do not give as complete a record of strain in each mini-surge as one would like, a consistent overall pattern of long-interval strain versus time emerges from the data in Figure 18. It consists of an initial strong compressive swing, terminated by a rather abrupt break to a slight and varying but definite extension, after which the strain settles down to a steady compression rate as before the mini-surge. The magnitude of the swing in compressive strain, $1-3 \times 10^{-4}$, is comparable to that in the measurements of Raymond and Malone (1986). The strongest extension feature is in Figure 18c; it is a weak but definite extension peak, followed by some extra compression before the final state of steadily accumulating compression is attained. To the extent that an extension peak is recognizable in the strain curves of Figure 18, the curves approach the form portrayed by Raymond and Malone (1986, fig. 5) for event $80-5$ at $\mathrm{Km} 7.0$. In fact, Figure $18 \mathrm{e}$ is the longinterval strain during event $80-5$ for the interval $(\mathrm{Km} 7.0-7.3)$ in which Raymond and Malone's strain meter at $\mathrm{Km} 7.0$ was situated; it resembles Raymond and Malone's curve fairly well, although its extension feature is rather weaker than theirs. Strain curves in Figure 18, in which the extension peak is very weak or absent, resemble the curve for event 81-5a given by Raymond and Malone (1986, fig. 6 ). These comparisons show that the measurements of longinterval strains over distances of $670-740 \mathrm{~m}$ (or about $365 \mathrm{~m}$ in Figure $18 \mathrm{e}, \mathrm{f})$ give results rather similar to measurements of local strain over an interval of $10 \mathrm{~m}$.

For each of the strain curves in Figure 18, an arrow is placed at the time of the peak in flow motion at the upper end and, separately, at the lower end of the strainmeasurement interval, based on the data in Figures 7-9. Where the motion peak was not observed directly, the shaft of the arrow is shown dashed; in this case, the arrow is placed at a time linearly interpolated between observed motion peaks on the basis of distance, which assumes
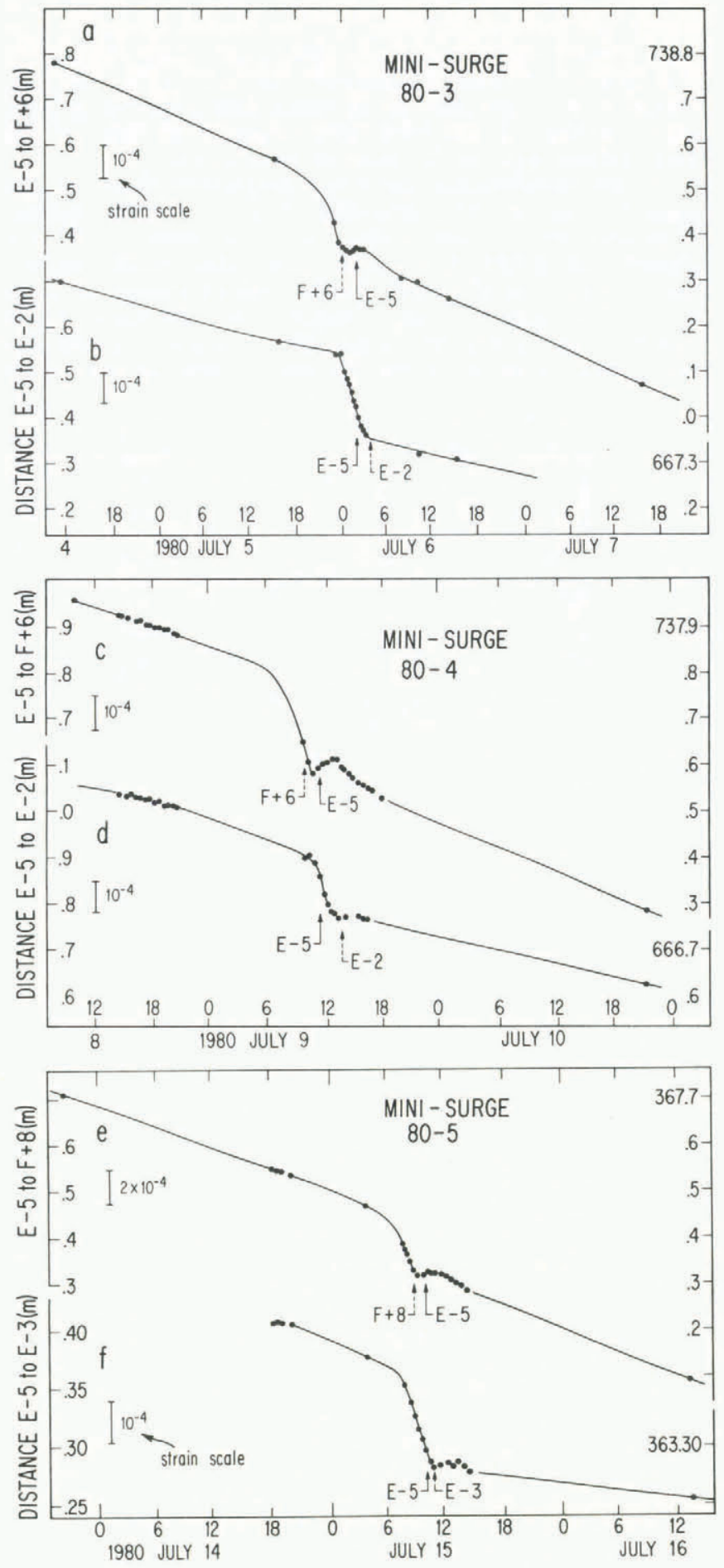

Fig. 18. Long-interval strain data from mini-surges in 1980 , for two strain-measurement intervals down-stream from $\mathrm{Km}$ 6.5: event 80-3: (a) from station $\mathrm{F}+6$ to $\mathrm{E}-5$ ( Km 6.5-7.3); (b) E-5 to E-2 (Km 6.5-8.0), event 80-4; (c) $\mathrm{F}+6$ to $\mathrm{E}-5$; (d) $\mathrm{E}-5$ to $\mathrm{E}-2$, event $80-5$ : (e) $\mathrm{F}+8$ to $\mathrm{E}-5$ $(\mathrm{Km} \mathrm{7.0-7.3);} \mathrm{(f)} \mathrm{E-5} \mathrm{to} \mathrm{E-3} \mathrm{(} \mathrm{Km} \mathrm{7.3-7.7).} \mathrm{Abscissa} \mathrm{scales}$ are in hours. Ordinate is measured distance between stations (the total distance appears alongside the ordinate scale on the right). Magnitude of the corresponding strain changes is indicated by the strain scale-bar adjacent to each ordinate scale on the left. Curves are drawn as interpolations/interpretations based on the data points. Each arrow shows the time of the flow-velocity peak at the station indicated; where the shaft of the arrow is dashed, the plotted time is an interpolation between actually measured peak times as explained in the text. 
constant propagation rate for the motion peaks over the longitudinal intervals involved. The arrows are seen to bracket consistently the sharp break (hereafter called the "break point") that terminates the compression swing of the long-interval strain curves, the bracketing being closest for the shortest distance-measurement intervals (Fig. 18e, f) These results imply that as the measurement interval goes to zero, the time of the break point tends to the time of the flow-velocity peak at the point of observation.

This identification allows the propagation speed of the motion peak to be determined from the strain curves. Raymond and Malone (1986) used the break point for determining propagation speed from their strain curves, noting that it is the most sharply defined feature in these curves. Propagation speeds obtained from the long-interval strain curves in Figures 18 and 19, on the assumption that each break point represents the motion peak at the center
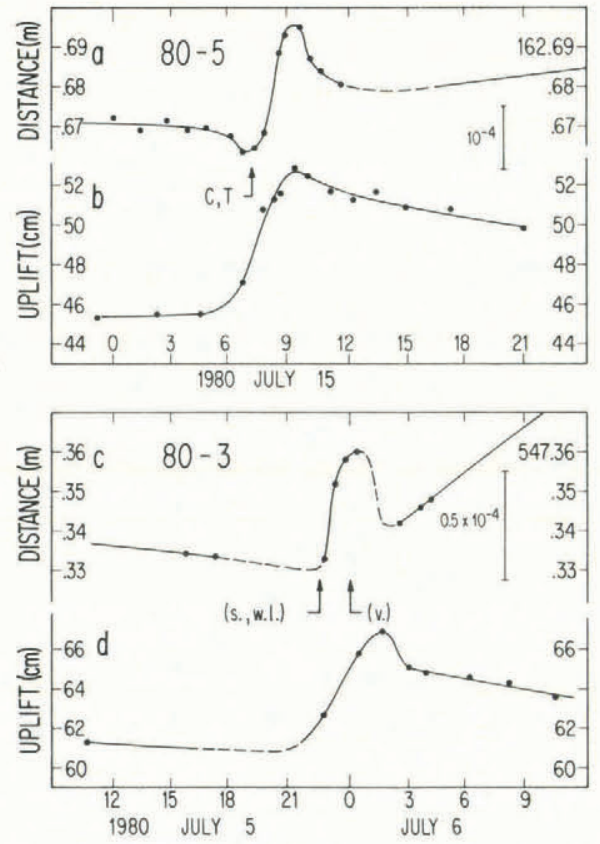

Fig. 19. Long-interval strain data from the reach $\mathrm{Km} 6.0-6.5$ for mini-surges in 1980: (a) event 80-5, strain interval from station C to $\mathrm{F}+6 \quad(\mathrm{Km} 6.4-6.5) ; \quad(c)$ event 80-3, interval from $\mathrm{F}+4$ to $\mathrm{F}+6(\mathrm{Km} 6.0-6.5)$. (b) and (d) show, for comparison, uplift measured at station $\mathrm{T}(\mathrm{Km} 6.5)$ for the two mini-surges, from Figures $7 e$ and $10 d$. Strain curves in (a) and (c) are drawn as interpretations from the data points; the slopes of the curves near the edges of the plots are drawn on the basis of measured points outside the time windows of the plots. Ordinate is measured distance between stations: corresponding strain changes are indicated by the strain scale-bar on the right. Abscissa is in hours. In (a), the arrow indicates time of flow-velocity peak at stations $\mathrm{c}$ and $\mathrm{T}$. In (c), the arrow labeled "(s., w.l.)" indicates the time of the peak in seismicity at Km 6.6 and the peak in water level in bore hole vs at $K m 6.4$ (Fig. 7a, b); the arrow labeled "(v.)" indicates the time of the velocity peak at $\mathrm{Km} 6.5$ (station $\mathrm{T}$; Fig. 7d), which is also probably the time of the velocity peak at $\mathrm{Km} 6.0$ (station $\mathrm{F}+4 ;$ Fig. $7 \mathrm{c}$ ).

of the longitudinal interval over which the strain is measured, are listed in Table III for wave type "Ls". These speeds lie in the narrow range $0.25-0.29 \mathrm{~km} / \mathrm{h}$, slower and more closely clustered than the other speeds in Table III, column 6.

Long-interval strain curves from our data near $\mathrm{Km}$ 6.0-6.5 for mini-surges $80-3$ and $80-5$ have some prominent features not seen in the strain curves farther down-glacier. They are given in Figure $19 \mathrm{a}$ and c. Figure $19 \mathrm{a}$ is the best curve, having good strain coverage right through the main mini-surge action of event $80-5$, measured over a $163 \mathrm{~m}$ interval at $\mathrm{Km} 6.4-6.5$. It shows a rather small initial compression, with a short, small minimum coincident with the peak in motion (arrow in Figure 19a); then the strain curve breaks and swings strongly to extension, forming an extensile peak well above the initial strain. Similar but less complete strain data for interval $\mathrm{Km} 6.0-6.5$ in event 80-3 are given in Figure 19c. (Here, two separate arrows are placed for the flow-velocity peak and the peaks of water level and seismicity, because there is a discrepancy of $2.5 \mathrm{~h}$ between them in Figure 7 , as discussed in section 7.) These strain curves can be thought of as derivable from the curves of Figure 18 by great enhancement of the extensile peak and suppression of the initial compressional swing. In having the strong extensile peak, these longinterval strain curves seem related to the "double-wave pattern" of short-interval strain observed in several minisurges of 1979 by Raymond and Malone (1986). However, the "double-wave" curves depicted by Raymond and Malone (1986, figs 3 and 4) differ from the long-interval strain curves in Figure $19 \mathrm{a}$ and $\mathrm{c}$ in having a much more pronounced swing of initial compression.

\section{INTERPRETATION OF THE MINI-SURGES}

The foregoing observations, together with the observations of Raymond and Malone (1986) and Humphrey and others (1986), serve to define a repeating, reproducible glacier-flow phenomenon that has significance both as a flow phenomenon in its own right and in relation to the mechanisms of glacier surging.

\subsection{Cause of mini-surge flow}

The invariable association of a water-pressure wave with the flow-velocity wave in the mini-surges indicates that the waves form a coupled system and therefore interact with and influence one another. The primary influence is the effect of the water-pressure wave on the flow of the glacier, as the following considerations imply. The basal water pressure corresponding to a water level standing about $40 \mathrm{~m}$ below the glacier surface is equal to the ice-overburden pressure at the base of the ice mass, which was about $375 \mathrm{~m}$ thick in the vicinity of $\mathrm{Km} \mathrm{6.5}$. When the water rises above this level, as it does in the early part of the pressure wave, the basal water pressure becomes more than sufficient to float the glacier* if it were applied long enough from a source with a sufficiently large volume of water available at this pressure. Such a drastic state of affairs must inevitably result in an uplift of the glacier as a whole and an increase in its basal sliding velocity. The fact that both the uplift and the flow speed-up are observed in close association with each pressure peak in which the water level rises above the $36 \mathrm{~m}$ below-surface level (section 3) makes it quite compelling that they are caused by the high water pressure, and that rapid basal sliding is responsible for the high flow velocities observed at the glacier surface.

The relationship between basal water pressure and glacier-flow velocity in the mini-surges of Variegated Glacier is indicated by Figure 20, in which measured flow velocities at station $\mathrm{T}$ are plotted against the concurrent

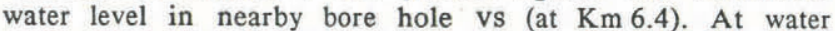
levels lower than about $80 \mathrm{~m}$ below the surface, the basal water pressure appears to have little or no influence on flow velocity. A major break occurs at about the $40 \mathrm{~m}$ below-surface level, above which the observed velocities increase greatly as a function of increasing pressure but with much scatter, indicating that not a single, univariant relationship is involved. (The open circle with attached arrow, which is for event $80-2$, should lie higher, as the arrow suggests, because the velocity plotted is an $11.5 \mathrm{~h}$ average rather than the actual peak velocity accompanying

*For an ice mass $375 \mathrm{~m}$ thick, a "flotation water level" at $40 \mathrm{~m}$ depth corresponds to a mean density of $0.89 \mathrm{Mg} \mathrm{m}^{-3}$ for the ice (plus firn) column. For mean densities in the range $0.85-0.92 \mathrm{Mg} \mathrm{m}^{-3}$, the "flotation level" ranges from 30 to $56 \mathrm{~m}$. 


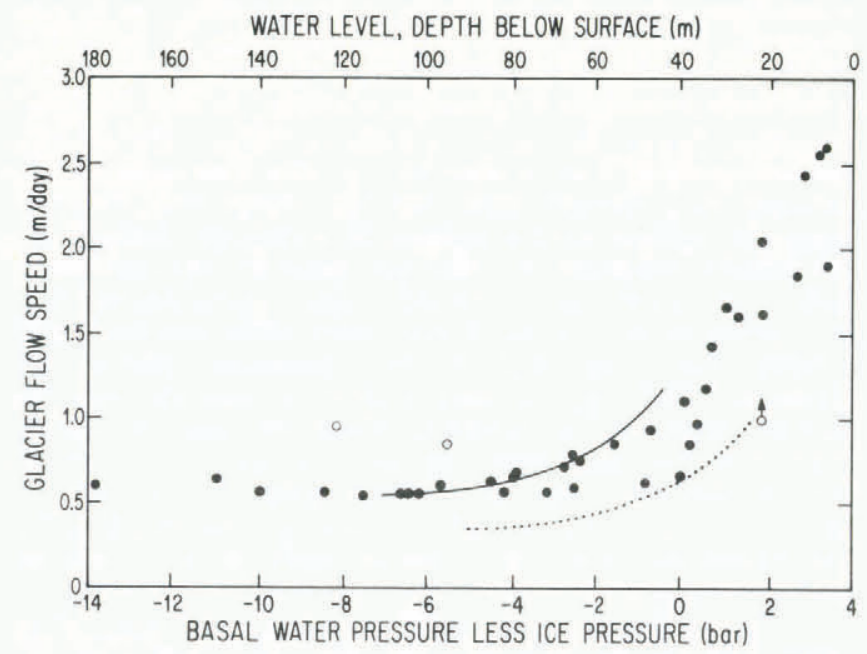

Fig. 20. Relationship between basal water pressure and short-term flow speed of Variegated Glacier at Km 6.5 in 1980. In the upper ordinate scale, water pressure is expressed in terms of water level in a bore hole that is well connected to the basal water system (bore hole vs, at $\mathrm{Km}$ 6.4), the level being given as depth below the glacier surface. In the lower scale, basal water pressure is given relative to the ice-overburden pressure for a "flotation level" at depth $40 \mathrm{~m}$ (corresponding to an ice thickness of $375 \mathrm{~m}$ and mean density of $0.89 \mathrm{Mg} \mathrm{m}^{-3}$ ). Points are taken from data in Figures 4, 5, 7, 8, and 10, and from similar data between mini-surges. Open circles are peculiar points discussed in the text. Dotted curve is regression curve of data from Findelengletscher (Iken and Bindschadler, 1986, fig. 6); this is translated into the solid curve by a shift of $20 \mathrm{~m}$ in water level and $0.21 \mathrm{~m} / \mathrm{d}$ in flow velocity, as explained in the text.

the water-level maximum.) The break at the $40 \mathrm{~m}$ level in Figure 20 is a manifestation of the drastic effect of water pressures sufficient to float the glacier. In the interval between the 40 and $80 \mathrm{~m}$ levels, there is an indication of some influence of water pressure on flow; however, the data points scatter as much as the effect itself.

An increase in water pressure at the bed promotes basal sliding by causing basal cavitatin, which tends to reduce the basal drag stress in two ways: increased pressure on the cavitated areas of the sole, which are generally inclined down-glacier, gives a net down-glacier-directed traction component on the sole (Iken, 1973, p. 214); and ice separation from bedrock eliminates basal drag associated with sliding over any smaller-scale roughness features in the newly separated areas. Increased water also reduces frictional drag associated with basal rock debris. These reductions in drag stress must be compensated by an increase in the sliding speed. Detailed consideration of the above effects (Kamb, 1979; Iken 1981) shows that a marked increase in basal sliding should occur only for basal water pressures within a few bars of the ice-overburden pressure at the bed. The data in Figure 20 conform with this expectation.

The data pattern in Figure 20 resembles in a general way the curves of sliding velocity versus water pressure calculated theoretically by Iken (1981, fig. 8) for various bed and cavitation models and for various transient and steady-state conditions. Our observations extend, however, to much higher sliding velocities and water pressures - in fact, to water pressures considerably greater than the "limiting water pressure" above which the sliding is inferred theoretically to become unstable (Iken, 1981, p. 408).

When we consider that the period during which water levels stand higher than the "flotation level" lasts for about $12 \mathrm{~h}$ in the mini-surges, it is perhaps surprising that the acceleration in sliding velocity and the amount of uplift are no greater than they are. To some extent, this may be explained by the fact that the glacier remains constrained along its sides, where the flotation pressure at the bed is not exceeded. Also, the basal water pressure is in general somewhat lower than the hydrostatic pressure corresponding to the observed water level, because of down-flow through constrictions in the connection from the bore hole to the basal water system. However, it seems likely in addition that the high water pressure at the bottom is able to gain access to only a limited part of the bed during the $\sim 12 \mathrm{~h}$ period. The observed flow under the high water pressure thus represents a transient response. The fact that the data points in Figure 20 do not fall on a single curve but instead scatter greatly is probably a consequence of the transient character of the motion.

From Findelengletscher, Switzerland, Iken and Bindschadler (1986, fig. 6) have obtained an observational glacier-flow versus water-pressure relation, which is generally similar to Figure 20, except that the data points scatter relatively little about a single regression curve, suggesting that the data correspond to more nearly steadyflow conditions. The regression curve is shown as a dotted line in Figure 20. To take into account the difference in flotation level for Findelengletscher $(c .20 \mathrm{~m})$ and Variegated Glacier $(c .40 \mathrm{~m})$, the curve should be shifted to the left by $20 \mathrm{~m}$, thus increasing all water-level depth values by $20 \mathrm{~m}$ over those actually observed in Findelengletscher. In addition, to take into consideration the lower flow velocities at low water pressures, where water pressure has little or no influence on flow, the curve could be shifted up by $0.21 \mathrm{~m} / \mathrm{d}$, increasing all velocity values by this amount. The result of the two shifts is the solid curve in Figure 20 . It follows approximately the upper edge of the scatter of data points from Variegated Glacier, as is reasonable for a steady-state flow versus pressure relation toward which the transient-flow points would tend if given sufficient time to approach a steady state. If the glacier were infinitely wide, the steady-state relation would have a vertical asymptote at a water-level depth greater than $40 \mathrm{~m}$ by an amount that depends on details of the bedrock topography (Iken, 1981, p. 408). However, because of the constraints of the glacier side walls, the relation will doubtless extend to somewhat higher water levels (smaller water-level depths) without blowing up, as the pattern in Figure 20 suggests.

The lack of a mini-surge accompanying the high peak in water level labeled $3 \mathrm{~b}$ in Figure 16 (see section 6) may perhaps be an indication that the mini-surge that was caused by peak 3a (event 79-3), which preceded $3 \mathrm{~b}$ by about $1 \mathrm{~d}$, in some way "de-sensitized" the basal water system so that peak $3 \mathrm{~b}$ failed to cause a mini-surge. A concept of "de-sensitization" like this has been advanced by Raymond and Malone (1986) in connection with certain mini-surges of 1981. In the case of the pair of high water-level peaks $2 a$ and $2 b$ (Fig. 15d), it was the second (and higher) peak (2b) that coincided with the high seismicity peak (Fig. 15c) that is identified with event 79-2; but the moderate seismicity peak associated with peak $2 a$ (Fig. 15c, d) may indicate, as noted in section 6, that a separate, weaker mini-surge accompanied $2 a$, so that event 79-2 was actually a double event. If so, the first mini-surge did not de-sensitize the glacier enough to prevent the mini-surge caused by the higher water-level peak $2 b$.

\subsection{Significance of accompanying uplift: basal cavitation}

The uplift of the glacier surface in the mini-surges is compounded of two effects: (1) vertical strain associated with the ice deformation that accompanies the flow-velocity wave, and (2) basal cavitation.

The effects of the strain wave associated with the velocity wave can be calculated simply from the flowvelocity curve, if the velocity wave propagates down the glacier with unchanging form, and if the accompanying lateral strain is either known or negligible. If the wave of extra flow velocity $\Delta u$ propagates at velocity $V$ down the glacier (longitudinal spatial coordinate $x$ ) with constant wave form $\Delta u(x-V t)$, then by differentiating with respect to $x$ and integrating with respect to $t$ we find that the longitudinal strain change that would accompany the velocity wave is given by

$$
\Delta e_{x x}=-\frac{1}{V} \Delta u(x-V t)
$$


If this relation applies at all depths (as expected if the flow variations are due to variations in basal sliding), and if the flow variations are two-dimensional (no lateral expansion or contraction), then the strain-induced change in thickness (starting from initial thickness $h_{0}$ ) is

$$
\Delta h=h_{0} \Delta e_{z z}=\frac{h_{0}}{V} \Delta u(x-V t) .
$$

Thus the change in thickness would be proportional to the increase in flow velocity. A velocity increase $\Delta u$ of $250 \mathrm{~cm} / \mathrm{d}$, at the peak of event $80-5$, propagating at $V=$ $300 \mathrm{~m} / \mathrm{h}$, with $h_{0}=140 \mathrm{~m}$ (estimated ice thickness at station T), would correspond by Equation (2) to a peak uplift of $5 \mathrm{~cm}$, which is about half the amount of uplift observed (Fig. 10d).

The observations (sections 5, 6, and 9) differ from the predictions of Equations (1) and (2) in three significant respects. 1. Whereas, according to Equation (2), the uplift peak should occur in phase with the velocity peak, in fact the uplift peak always lags behind the velocity peak by about $2 \mathrm{~h}$; the maximum uplift rate always coincides with the peak in flow velocity, whereas according to Equation (2) the uplift rate should be zero at that time. 2 . The subsequent decay in uplift does not follow the curve of decaying velocity, as Equation (2) requires, but instead tends to follow the water-pressure curve. 3. Longitudinal strain observed near $\mathrm{Km} 6.5$ in events $80-3$ and $80-5$ (Fig. 19a, c), near station $\mathrm{T}$ where the uplift was measured, does not show the pattern required by Equation (1); this is discussed in section 10.6. The strain and uplift behavior do not , validate Equations (1) and (2), and the assumption of constant-form wave propagation on which they are based. This causes us to conclude that Equation (2) cannot be used to account for the uplift on the basis of the strain wave. In the case of events $80-3$ and $80-5$, the strain wave definitely cannot account for the uplift, because during the time of uplift (Fig. 19b, d) the longitudinal strain is mainly extensional, rather than compressional, as would be necessary to produce the uplift by the strain-wave mechanism.* Also, the magnitude of the observed longitudinal strain $\left(1.3 \times 10^{-4}\right.$ in the extensional peak of Figure 19a) is too small by a factor of about 5 to produce a vertical motion of $11 \mathrm{~cm}$, even if it had the right sign, which it does not.

Insofar as the above reasoning depends via Equation (2) upon the expectation that $\Delta u$ and $\Delta e_{x x}$ do not vary much with depth, it would seem to be called into question by the calculations of Balise and Raymond (1985) of surfacevelocity patterns accompanying zones of enhanced basal sliding. However, three features of the calculated results do not conform to the spatial pattern of surface velocity that our data for the mini-surge indicate (if the spatial pattern is related to the measured temporal pattern as expected for a propagating wave). 1. In the observed peaks in the horizontal velocity component there is little if any indication of the symmetrical double peaks given by the

*In comparing, for this argument, the strain curve in Figure 19d with the uplift curve in Figure 19c, the strain curve should, if the strain propagated down-glacier as a wave with a speed of $0.3 \mathrm{~km} / \mathrm{h}$, be shifted about $1 \mathrm{~h}$ to later times, because the strain-measurement interval was centered $0.25 \mathrm{~km}$ up-stream from station $\mathrm{T}$ where the uplift was measured. A shift of $1.5 \mathrm{~h}$ would make the strain "break point" (section 9) conform to the flow-velocity peak, but this is moot, because the flow-velocity peak at $F+4$ (Km 6.0) occurred at the same time as, or even somewhat later than, the velocity peak at $\mathrm{T}$ (Km 6.5) (see section 7). For the "break point" to conform to the seismicity and water-level peaks (Fig. 7a, b), the curve in Figure 19c should not be shifted. Within the range of ambiguity as to what shift is appropriate, it seems reasonable to think that the relationship between the curves in Figure $19 \mathrm{c}$ and $\mathrm{d}$ is the same as between the curves in Figure 19a and b, which would involve a shift of $1 \mathrm{~h}$. In this case, both strain curves (Fig. 19a, c) apply equally to the arguments given here as to the significance of the uplift. calculations for a Gaussian pulse in basal sliding (Balise and Raymond, 1985, fig. 5). 2. The observed peaks in horizontal velocity show a much sharper onset than is given by the calculations either for a Gaussian pulse or for a sharp front or steep ramp in basal velocity increase (Balise and Raymond, 1985, figs 4 and 5). 3. The calculated uplift patterns for a Gaussian pulse and for a sharp front or steep ramp, in relation to the pattern of horizontal velocity, do not closely resemble the observed patterns; for the sharp front or steep ramp, which best approximates the mini-surge onset, the uplift rate peaks when the horizontal velocity has risen only to half maximum (Balise and Raymond, 1985, fig. 4), instead of in coincidence with the velocity maximum, as observed. These discrepancies, which might possibly result from the use of a linear flow law in the calculations, seem to preclude using the results for interpreting the observed velocity patterns and in particular for concluding that the observed uplift is due only or mainly to strain.

The similarity of the uplift curves for all events (Figs 4-10) leads us to think that the same basic cause of the uplift applies to all. From the above considerations we conclude that at least a major part of the observed uplift comes not from the strain wave but rather from some other source, which is closely associated with the pressure wave. We think that this source is cavitation at the glacier bed, caused by the high basal water pressures, and promoted additionally by the high sliding velocity that develops in the mini-surges. This interpretation is particularly supported by the fact that the maximum sliding velocity always coincides with the maximum uplift rate (section 4), a relationship that is characteristic of basal cavitation as shown by the calculations of Iken (1981). The lag between the abrupt rise in water pressure is interpreted as the time for growth of the basal cavities once the high water pressure is applied.

To the extent that the uplift is due to basal cavitation, the amount of uplift is an areal average of the thickness of the cavities formed. Thus, if cavities actually form over $10 \%$ of the glacier bed, and the observed surface uplift is $5 \mathrm{~cm}$, then the actual cavity thickness, averaged over the cavitated areas, is $50 \mathrm{~cm}$.

The strong turbidity peak seen in the outflow stream in connection with each mini-surge (Humphrey and others, 1986) can be explained as the consequence of enhanced basal cavitation giving basal water temporary access to rock debris over an increased area of the glacier bed. Cavitation that either increases the size of existing water conduits or creates new conduits through which water can flow fast enough to entrain suspendable sediment (glacial flour) will contribute to increased turbidity in water moving through the basal water system toward the outflow stream portal.

It appears that in the mini-surges the amount of cavitation remains approximately constant for several hours after the peak uplift, before beginning to drop back toward the pre-mini-surge level. This is indicated by the trajectories followed by the points in Figure 11: the uplift peak is followed by a small drop (which may be due to the tail of the strain wave), after which the uplift remains for a time approximately constant relative to the base line defined by points in the non-mini-surge intervals. By relating the points in Figure 11 to the velocity and waterlevel curves in Figures 4,5 , and 7 , it is ascertained that the drop in cavitation begins when the water level reaches a depth of $50-70 \mathrm{~m}$, and when the flow velocity has dropped back essentially to the "normal", non-mini-surge level. The lag in decrease of cavitation may indicate that, as the basal water pressure drops, the connections of the newly formed cavities with the through-going basal water system tend to close off, trapping water for a time in these cavities, which prevents the cavities from re-closing. This explanation was given by Iken and others $(1983$, p. 36) for similar uplift behavior observed on Unteraargletscher.

Distinct from the short-period, transitory uplifts associated with the mini-surges in the much slower uplift of about $10 \mathrm{~cm}$ that occurred over the period 14-27 June 1980, starting at the beginning of the summer-time flow regime (section 4). It may be interpreted as due to cavitation associated with the increasing sliding velocities of the "normal" summer-time regime, and is very similar in this 
respect to (but smaller than) the "extended uplift" of Unteraargletscher that has been similarly interpreted by Iken and others (1983). The contrast in slope between a steeper "winter-time" trend (dash-dot line in Figure 11) and a shallower "summer" trend (dashed line) is a feature also observed in Unteraargletscher (Iken and others, 1983, fig. 2). The $10 \mathrm{~cm}$ uplift in Figure 11 did not decay during the period of observation, according to the way the dashed line is drawn, whereas in Unteraargletscher, where the long-term trends were better established by observations through more than a full year, the corresponding "extended uplift" of $40 \mathrm{~cm}$ was seen to decay away slowly over the period July-November.

\subsection{Premonitory effects}

The preliminary velocity increase in the mini-surges, immediately prior to the main speed-up that accompanies the arrival of the water-pressure wave, is interpretable as due to the forward shove that the main speeded-up mass exerts on the ice ahead of it. A theoretical analysis of the longitudinal velocity profile in the leading edge of the flow wave, based on the longitudinal coupling theory of Kamb and Echelmeyer (1986), indicates that this influence on the flow should extend over a distance of about $1.5 \mathrm{~km}$ ahead of the wave peak, and this agrees reasonably with the approximately $3 \mathrm{~h}$ time-scale of the preliminary velocity rise. This preliminary speed-up, which is presumably accommodated in part by increased basal sliding, should lead to some preliminary basal cavitation, since the extent of cavitation should be an increasing function of sliding velocity for given ice-overburden pressure and basal water pressure. The preliminary opening of basal cavities can explain the preliminary drop in water level that is usually observed just before the water wave arrives. The two opencircle points in Figure 20 corresponding to water depths of about 95 and $120 \mathrm{~m}$ represent conditions at the time of water-level drop just before mini-surge, which explains why they fall so far off the general trend of the other points.

The premonitory velocity increase over a period of $1 \mathrm{~d}$ or more before some mini-surges, discussed in section 4 , may be due to a premonitory rise of water pressure to relatively high levels (water level $40-70 \mathrm{~m}$ below the surface) during these periods. In Figures 13 and 14 , such a rise can be clearly seen preceding events 79-2, 80-4, and $80-5$, for which premonitory velocity increases were observed. Whether the substantial premonitory increases before events $80-1$ and $80-2$ were accompanied by rises in water pressure cannot be ascertained, because no bore hole was connected to the basal water system at that time.

Alternatively, a premonitory increase in flow velocity somewhere up-stream, in the source region of a mini-surge (see section 10.7), can cause an increase in velocity downstream, through longitudinal stress-gradient coupling; as noted above, such an influence can be exerted if the source region is not more distant than about $1.5 \mathrm{~km}$. This seems to have been the case in event $80-2$, as indicated by EDM data for the line from $F+4$ to $G$, which showed a large premonitory velocity increase in the tributary. In event 80-5 there was a large premonitory velocity increase in the upper glacier near $\mathrm{Km} \mathrm{4-5}$ over the period 11-14 July; this probably caused, by longitudinal coupling, the modest premonitory velocity increase observed at $\mathrm{Km} 6.5$ (Fig. 3).

\subsection{Seismicity}

The correlation of peak seismicity with the peak of the flow-velocity curve may imply that the predominating seismic activity occurs in zones of high shear between the mini-surging ice stream and peripheral parts of the glacier that do not experience the speed-up effect of increased basal water pressure. However, there must also be a widely distributed seismicity, corresponding to the widespread fresh cracking of the glacier surface that is observed in minisurges, which is similar to the widespread crevassing in very fast-moving and surging glaciers.

\subsection{Mini-surge wave propagation}

What causes the wave propagation, and what determines the propagation velocity?

It is immediately clear that we are not dealing with a classical kinematic flow wave in the glacier, because the propagation velocity $(\sim 400 \mathrm{~m} / \mathrm{h})$ is vastly greater than the kinematic wave velocity indicated by glacier-flow theory $(\leqslant 15 \mathrm{~m} / \mathrm{d})$. The propagation of the mini-surge waves is thus not determined primarily by the flow characteristics of the glacier. Instead, it is determined, we think, by the propagation of the water-pressure waves.

Analysis of water flow in the basal water system, and its role in longitudinal adjustment of the distributed storage of water in basal cavities and intraglacial porosity (moulins, etc.) having access to the bed, leads to a simple mathematical model of water-pressure wave propagation and defines the conditions required for such propagation. It shows that if the laterally averaged hydraulic conductivity $k$ of the basal water system is longitudinally constant, there will be no wave propagation but only a diffusive dissipation of any wave-like features in the phreatic (piezometric) surface. For a wave to propagate down-glacier, $k$ must increase up-glacier in the reach where the wave is propagating. The up-glacier increase in basal cavitation that is produced by the down-glacier-facing front of high water pressure in the mini-surges has as an inherent consequence an up-glacier increase in $k$. The down-glacier propagation of this front, as a traveling wave, therefore arises as a natural and inherent consequence of the coupling of water pressure to basal cavitation. These ideas are developed quantitatively in a separate paper (in preparation by Kamb and others). From the mathematical model developed, the wave-propagation velocity can be calculated, and it agrees in order of magnitude with the observed velocities, which suggests that the basic physical picture of wave propagation contained in the model is correct.

In this concept, the flow-velocity wave arises as a consequence of the pressure wave and propagates with it, with only relatively minor longitudinal adjustment that results in the preliminary velocity increase discussed in section 10.3. The flow wave reacts back on the pressure wave via the initial pressure drop (also discussed in section 10.3 ) and, in addition, via the mechanical role of enhanced basal sliding in promoting basal cavitation, an effect that adds to the cavitation caused directly by high pressure.

A significant feature of the wave propagation is the attenuation of the velocity and pressure waves down-glacier. Within the framework of the model discussed above, the attenuation of the water-pressure wave arises from a diffusion-like spreading that has the same physical basis as when $k$ is longitudinally constant. Of even more interest is the enhancement of the velocity wave as it moves down through the region above station $\mathrm{c}$, as observed in event 80-5 (Fig. 9a, b, c). The growth of the wave here may have some aspects of the development of a shock wave.

Wave growth and attentuation are aspects of longitudinal changes in the propagating wave form, which bear on the discussion in section 10.2 as to constancy versus non-constancy of the wave form. Another aspect, seen in Figure $9 a-c$, is the occurrence in event $80-5$ of a movement peak simultaneously along the length of the glacier from $\mathrm{Km} 4$ to $\mathrm{Km} 6.5$, the synchronous speed-up decreasing in magnitude up-glacier. At $\mathrm{Km} \mathrm{6.5,} \mathrm{this} \mathrm{is} \mathrm{the}$ main peak of the mini-surge, while up-glacier the simultaneous speed-up occurs several hours after the initial peak that we have interpreted as the arrival of the propagating mini-surge wave, marked with an arrow in Figure 9a, b. From this evidence, it appears to us that, when the pressure wave reached the vicinity of $\mathrm{Km} 6.5$ in event $80-5$, it triggered a particularly large increase in the flow velocity there, so large that by longitudinal stress interaction this caused a renewed acceleration of the flow up-glacier where the passing pressure wave had already caused a smaller velocity peak $3-6 \mathrm{~h}$ earlier. That such an influence this far up-glacier can be exerted by the speed-up near $\mathrm{Km} 6.5$ is understandable within the framework of longitudinal coupling theory, because behind the mini-surge wave front, where the flow is accelerated to surge-level speeds, the longitudinal coupling length is greatly increased over its normal value (Kamb and Echelmeyer, 1986, section 5).

10.6 Relation between flow velocity and longitudinal strain

It can be shown that strain curves of the type in Figure 18 are reasonably compatible with the observed 
flow-velocity curves in Figures $7-9$ in the sense that the strain and velocity curves approximately satisfy a relationship for wave propagation like Equation (1) (or its longinterval strain equivalent), generalized to take into account longitudinal variation of pulse amplitude, as done by Raymond and Malone (1986).

In contrast, the strain curves in Figure 19a, c are not compatible with such a relationship, as noted in section 10.2. These strain curves do not at all resemble (with sign changed) the flow-velocity curves (Figs 7c, d and 9c, d) as Equation (1) would require; the incompatibility cannot be remedied by inclusion of possible longitudinal variation of pulse amplitude, by the methods of Raymond and Malone (1986). The initial compressive swing in the strain curves is too weak by a factor of 5 or 10 , but the big stumbling block is the large extensile peak that follows. In order to interpret strain curves of this type as due to propagation of a flow-velocity pulse, in the way analyzed by Raymond and Malone (1986), what the extensile peak requires is a reversed (up-stream) flow of the glacier at the time of the extensile peak. Nothing in the measurements of glacier movement (Figs 7c, d and 9c, d) makes believable a reversal in flow at this time, or even a deep minimum in flow without reversal. The time resolution of the velocity measurements is quite sufficient to reveal such a minimum if it had occurred.

It seems that to explain the strain curves near $\mathrm{Km} 6$ we must appeal to something special in the flow response of the glacier to the water-pressure pulse there, such that the constraints based on propagation of a movement pulse, Equation (1) or its generalization, are broken. That there may be something of this kind in the response near $\mathrm{Km} 6$ is also suggested by the way in which the speed-up at $\mathrm{Km} 6.5$ in event $80-5$ appears to have triggered a simultaneous speed-up in the glacier up-stream from $\mathrm{Km} 6.5$, as just discussed (section 10.5). A longitudinally simultaneous speed-up would tend to suppress the initial compression that would occur for a propagating wave. The subsequent extensile peak could be due to longitudinal variation in the shape of the trailing part of the flow-velocity curve. A difference in velocity of $0.25 \mathrm{~m} / \mathrm{d}$ (on average) between stations $\mathrm{c}$ and $\mathrm{F}+6$ over the $2 \mathrm{~h}$ period from onset to maximum of the extensile peak would be sufficient to cause the accumulation of the observed $2 \mathrm{~cm}$ of extension (Fig. 19a). The occurrence of velocity difference of this magnitude is not improbable, because such differences are seen in comparing the measured velocity data at $\mathrm{C}$ and $\mathrm{T}$ (Fig. 9c, d), although such differences are near the limit of reliable detection for velocity values of $1 \mathrm{~h}$ time resolution (section 4).

\subsection{Source of the water-pressure waves}

Where and how is water accumulated and released to form the water-pressure waves that cause the mini-surges?

The full set of long-interval strain data from the station network in Figure 1, covering the complete field seasons of 1980 and 1981 and therefore too extensive for inclusion in this paper, shows that the area of origin or "source area" of the mini-surges tends to move up-glacier through the sequence of events each summer, as indicated by the "source area" notations in Table I. A similar conclusion was reached by Raymond and Malone (1986) from short-interval strain data. The first event of the summer has its source area near $\mathrm{Km} 6.5$. The next two events are usually initiated in the tributary, and then the source area moves up into the upper glacier near $\mathrm{Km} \mathrm{3-4}$ for the last two or so events. The sequence seems to repeat itself from year to year, at least approximately, with only a few events deviating from the pattern (Table I).

This pattern suggests that the water-pressure waves are caused by the release of melt water that has been accumulated in subglacial (?) reservoirs in three or four specific regions of the glacier, the accumulation and release coming earlier at lower elevations and in south-facing areas (the tributary) because of the earlier onset of surface melting there. At the upper end of each reach that appears to act as a source area is a conspicuously flat area of the glacier surface, suggesting the presence of a subglacial basin or lake, which could be the site of a subglacial reservoir.
In several mini-surge events $(80-2,80-3$, and $80-5$; also $81-6)$ a large, gradual premonitory build-up of flow velocity in the source area was observed over a period of 3-4 d prior to the mini-surge event. The premonitory build-up was in some cases seen in attenuated form lower in the glacier, near $\mathrm{Km} \mathrm{6.5,} \mathrm{probably} \mathrm{as} \mathrm{a} \mathrm{result} \mathrm{of}$ longitudinal stress-gradient coupling with the source area up-stream (see section 10.3). It seems likely that the premonitory velocity build-up in the source area reflects a gradual build-up there of basal water pressure and an accumulation of basal and intraglacial water, which is then released to form a propagating wave as the mini-surge is initiated.

These relationships will be further discussed in a later paper, oriented toward the mechanism of water storage and release, and based particularly on observations made in the source area in the upper glacier in 1981.

\section{COMPARISON WITH MOVEMENT EVENTS IN OTHER GLACIERS}

Short-term movement events having a number of similarities to the mini-surges of Variegated Glacier have been observed in two glaciers in the Swiss Alps: Unteraargletscher (Flotron, 1973; Iken, 1977; Röthlisberger, 1980; Iken and others, 1983) and Findelengletscher (Iken and Bindschadler, 1986).

In Unteraargletscher, as observed in 1970-76 (unpublished information from A. Flotron), three or four movement events occurred each summer, at intervals of 10-30 d during the period mid-May to late June (and also, rarely, an event in September), similar in an overall way to the timing of the mini-surges (section 3). The events were always associated with an uplift of the glacier surface, amounting to $10-20 \mathrm{~cm}$, and the maximum uplift rate coincided with maximum flow velocity, as in the mini-surges (section 5). The uplift is interpreted as due to basal caviation (Iken and others, 1983, p. 33), as in our interpretation of the mini-surges (section 10.2). Peak flow velocities in the Unteraargletscher events were two to five times faster than normal velocities, as in the mini-surges (section 4 ), but the velocity levels were much lower (normal, $5-8 \mathrm{~cm} / \mathrm{d}$; peak $15-35 \mathrm{~cm} / \mathrm{d})$. Flow velocity versus time had an approximately symmetrical peak, unlike the pronounced asymmetry of the mini-surge peaks (section 4 ). The duration of the Unteraargletscher events was generally several days, considerably longer than the $\sim 1 \mathrm{~d}$ duration of the minisurges, excluding premonitory build-up (section 4) and the possibly related several-day duration observed in the source region (section 10.7). One well observed event in Unteraargletscher on 27-29 June 1975 (Iken and others, 1983, fig. 3) was somewhat more mini-surge-like in terms of relatively short duration $(1.5 \mathrm{~d})$ and high peak velocity $(60 \mathrm{~cm} / \mathrm{d})$, but the velocity peak was again symmetrical. The uplift peak was, however, markedly asymmetric - rapid uplift followed by slow decline, as in the mini-surges; the peak in accumulated uplift (not uplift rate) lagged beind the peak in flow velocity by about $8 \mathrm{~h}$, much longer than the $2 \mathrm{~h}$ lag in the mini-surges (section 5). Information bearing on possible longitudinal propagation of the Unteraargletscher events was obtained only in the short-duration event just cited, for which a slight, down-glacier increasing time delay of the movement peak, at the limit of detection (delay of less than $1 \mathrm{~d})$, was observed. A seismicity event was detected on the glacier in late May 1977, and appears to have been associated with a movement event (Deichmann and others, 1979). The close relation between the Unteraargletscher events and periods of strong melt (Iken and others, 1983, p. 32 ) is not a feature of the mini-surges that we have recognized, although the general timing of occurrence in the early part of the melt season is common to the Unteraargletscher events and the mini-surges.

There are enough features in common between the Unteraargletscher movement events and the mini-surges to make a close relationship between the two types of events quite evident. It is thus very likely that the Unteraargletscher events are caused by peaks of high basal water pressure, as argued by Iken (1977), Röthlisberger (1980), and Iken and others (1983), although direct evidence 
for this is lacking. Certain detailed characteristics of the Unteraargletscher events, particularly the relatively long duration and the lack of asymmetry of the movement peaks, make these events appear more nearly akin to the minisurges in their source regions (section 10.7) than in the reach where well-defined down-glacier propagation is observed.

In Findelengletscher, a movement event linked to a down-glacier-propagating peak of bore-hole water level, surface uplift, and seismicity was observed on 30 May 1982, and two somewhat similar events, with less definite evidence of propagation, were seen on 16 June 1980 and 12 June 1982 (Iken and Bindschadler, 1986). The water-level peaks in the 30 May 1982 event (Iken and Bindschadler, 1986, figs 4 and 8) are similar to the peaks associated with the mini-surges in terms of peak asymmetry (rapid rise, slower decline), peak level (6-15 $\mathrm{m}$ below surface; above the "flotation level" of $18 \mathrm{~m})$, duration $(12-24 \mathrm{~h})$, and downglacier propagation and attenuation. The post-event descent of the water pressure to unusually low levels is also a similar feature. The movement peaks are sharp (duration less than $1 \mathrm{~d}$ ) and fairly high (speed-up factor 1.5-2.0, peak velocity about $85 \mathrm{~cm} / \mathrm{d}$ ), and they coincide with the waterlevel peaks, within the time resolution. Their symmetry/ asymmetry and down-glacier propagation are less definitely observed than in the mini-surges, probably because the time resolution in the observations $(\sim 10 \mathrm{~h})$ was not sufficient; however, the 16 June 1980 event (Iken and Bindschadler, 1986, fig. 10) showed an indication of the type of asymmetry characteristic of mini-surges. A premonitory increase in flow velocity, over a period of $2-4 \mathrm{~d}$ prior to two of the Findelengletscher events, was observed. The uplift, measured in two of the events, was $3-6 \mathrm{~cm}$, somewhat asymmetrical (faster uplift, slower decline), the maximum uplift rate occurred in conjunction with maximum flow velocity, and the peak in accumulated uplift lagged behind the water-level peak by $4-5 \mathrm{~h}$; all of these features are similar to the uplift in mini-surges. The uplift is attributed primarily to basal cavitation (Iken and Bindschadler, 1986, appendix III), as is the uplift in the mini-surges (section 10.2). The propagation speeds indicated by the arrival times of the peaks in water level and seismicity at different stations spaced at longitudinal distances of $400-900 \mathrm{~m}$ are $0.10-0.18 \mathrm{~km} / \mathrm{h}$ in the 30 May 1982 event (Iken and Bindschadler, 1986, table I), rather slower than found for the mini-surges here (Table III). We can expect the speeds based on the water-level peak to be slower than the speed of the flow-velocity peak, if, as it appears, the shape of the water-level peak changes down-glacier in the same way that it does in Variegated Glacier (see section 8). The 12 June 1982 event propagated even more slowly $(0.06-0.10 \mathrm{~km} / \mathrm{h})$, but was also different in having a broader and lower peak in water level, below the flotation level, as though already attenuated up-glacier.

From the numerous close similarities detailed above, there is little doubt that the propagating movement and uplift events in Findelengletscher represent basically the same phenomenon as the mini-surges of Variegated Glacier. The differences (e.g. in propagation speed) doubtless stem from differences in the detailed state of the basal and intraglacial water systems and their response characteristics under increase in basal water pressure, as formulated in the model of mini-surge wave propagation (section 10.5). Whether or not the examples of the mini-surge phenomenon in the two glaciers have the same cause in terms of what happens in the build-up and release of water in the source regions (section 10.7) cannot be decided on the basis of the limited present evidence.

\section{RELATION BETWEEN MINI-SURGES AND MAIN SURGE}

During the mini-surges the flow of Variegated Glacier attained for a few hours a velocity at the lower end of the range later observed in the main surge, $>2 \mathrm{~m} / \mathrm{d}$ (Kamb and others, 1985). To what extent is a similar mechanism involved? It has been argued on the basis of bore-hole water-level data obtained during the surge that the immediate cause of the rapid surge motion is high basal water pressure (Kamb and others, 1985, p. 476). The chain of evidence and logic for high basal water pressure as the causative agent for rapid glacier motion is even more compelling in the mini-surges (section 10.1). The two phenomena are thus related, but how closely?

The closest relation, it appears, is between the minisurges and the surge pulses, which are peaks of surge velocity that were associated with peaks in basal water pressure and propagated down the surging glacier at speeds of $0.3-0.6 \mathrm{~km} / \mathrm{h}$, the pulses occurring about every $5-7 \mathrm{~d}$ during late June to late July of 1982 and early June to early July of 1983 (Kamb and others, 1985, p. 470-73). Both of these propagating-wave phenomena can be accounted for with the same basic model for propagation of a pressure wave in the basal water system discussed in section 10.5. The differences in propagation speed (higher in the surge) and longitudinal attenuation (less in the surge) are attributable to differences in the state of the basal and intraglacial water systems and their response to increased water pressure, as are the differences between the minisurges in Variegated Glacier and Findelengletscher discussed in section 11. Some of the surge pulses in 1982 originated near $\mathrm{Km} 3$ in a process that took place on a time-scale of several days, similar to mini-surge initiation (section 10.7), and it therefore seems likely that a similar process of build-up and release of basal and/or intraglacial water was involved.

On the other hand, the initial build-up of basal water pressure in the surge probably took place by a different mechanism, because it occurred in mid-winter, when there was no available water source in surface melting (Kamb and others, 1985).

The high outflow turbidity generated by each minisurge (Humphrey and others, 1986) has a notable counterpart in the abnormally high turbidity of the outflowstream water during the main surge (Kamb and others, 1985 , p. 476). In both phenomena it is attributed to enlarged access, via cavitation, of the basal water system to glacial flour at the bed (section 10.2; Kamb and others, 1985 , p. 478). An additional source could be a greater production rate of glacial flour in the rapid basal sliding motions of the surge and the mini-surges.

The mini-surges were in some sense premonitory to the main surge, in that they occurred in well-developed form during at least the last four summers prior to the surge, whereas none seems to have occurred in the summers since the surge (personal communication from $W$. Harrison and C.F. Raymond). (A mini-surge did occur $18 \mathrm{~d}$ after surge termination, propagating down from about $\mathrm{Km} 9$ to about $\mathrm{Km} 15$ at a speed of $700 \mathrm{~m} / \mathrm{h}$ (Kamb and others, 1985, p. 473); thus, basal conditions favorable to initiation and propagation of waves of high basal water pressure continued for at least this long after termination of the actual surge.) Present evidence is insufficient to reach a definite conclusion as to whether or not mini-surges are a particular characteristic of surge-type glaciers prior to surge. Arguing seemingly to the contrary is the occurrence of the minisurge phenomenon in Findelengletscher and Unteraargletscher (section 11), which are not recognized to be of surging type. However, Findelengletscher in 1980 experienced a strong general speed-up and terminal advance, without apparent cause in terms of climatological and mass-balance factors, and with some surge-type features in terms of the development of debris-loaded shear discontinuities near the margins (personal communication from A. Iken); this may possibly be considered a mild surge. In the case of Unteraargletscher, it is not certain that its movement events are fully equitable with mini-surges (see section 11).

\section{ACKNOWLEDGEMENTS}

This work was made possible by grant DPP79-02584 from the U.S. National Science Foundation. We acknowledge the cooperation of the U.S. Forest Service, Tongass National Forest, and the U.S. National Park Service, Wrangell-St.Elias National Park, in giving permission for the field work. Drs C. Raymond and S. Malone kindly provided the seismicity data in Figures $7,8,10$, and 15-17. Logistical support was ably provided by Livingston Helicopters, Inc. 
The field work was carried out with the help of W. Power, J. Power, P. McMurtry, J. McLean, N. Sevitz, B. Quinn, G. Glassmoyer, T. Brian, A. Kamb, and C. Bretherton. We thank C. Raymond and W. Harrison and their field parties on Variegated Glacier for much cooperation and help in the field.

\section{REFERENCES}

Balise, M.J., and Raymond, C.F. 1985. Transfer of basal sliding variations to the surface of a linearly viscous glacier. Journal of Glaciology, Vol. 31, No. 109, p. 308-18.

Bindschadler, R., and others. 1977. Geometry and dynamics of a surge-type glacier, by R. Bindschadler, W.D. Harrison, C.F. Raymond, and R. Crosson. Journal of Glaciology, Vol. 18, No. 79, p. 181-94.

Bindschadler, R., and others. Unpublished. Variegated Glacier studies - 1975, by R. Bindschadler, W.D. Harrison, and C.F. Raymond. [Available from World Data Center A for Glaciology.]

Deichmann, N., and others. 1979. Observations of glacier seismicity on Unteraargletscher, by N. Deichmann, J. Ansorge, and H. Röthlisberger. Journal of Glaciology, Vol. 23 , No. 89 , p. 409.

Engelhardt, H.F., and others. 1978. Basal sliding and conditions at the glacier bed as revealed by bore-hole photography, by H.F. Engelhardt, W.D. Harrison, and B. Kamb. Journal of Glaciology, Vol, 20, No. 84, p. 469-508.

Flotron, A. 1973. Photogrammetrische Messung von Gletscherbewegungen mit automatischer Kamera. Photogrammetrie und Kulturtechnik, Jahrg. 71, Ht. 1/73, Fachblatt, p. 15-17.

Harrison, W.D., and others. 1986. Short period motion events on Variegated Glacier as observed by automatic photography and seismic methods, by W.D. Harrison, C.F. Raymond, and P. MacKeith. Annals of Glaciology, Vol. 8, p. 82-89.

Hodge, S.M. 1976. Direct measurement of basal water pressures: a pilot study. Journal of Glaciology, Vol. 16, No. 74 , p. $205-18$.

Humphrey, N., and others. 1986. Discharges of turbid water during mini-surges of Variegated Glacier, Alaska, U.S.A., by N. Humphrey, C. Raymond, and W. Harrison. Journal of Glaciology, Vol. 32, No. 111, p. 195-207.
Iken, A. 1973. Schwankungen der Oberflächengeschwindigkeit des White Glacier, Axel Heiberg Island. Zeitschrift für Gletscherkunde und Glazialgeologie, Bd. 9, Ht. 1-2, p. 207-19.

Iken, A. 1978. Variations of surface velocities of some Alpine glaciers measured at intervals of a few hours. Comparison with Arctic glaciers. Zeitschrift für Gletscherkunde und Glazialgeologie, Bd. 13, Ht. 1/2, 1977, p. 23-35.

Iken, A. 1981. The effect of subglacial water pressure on the sliding velocity of a glacier in an idealized numerical model. Journal of Glaciology, Vol. 27, No. 97, p. 407-21.

Iken, A., and Bindschadler, R.A. 1986. Combined measurements of subglacial water pressure and surface velocity of Findelengletscher, Switzerland: conclusions about drainage system and sliding mechanism. Journal of Glaciology, Vol. 32, No. 110, p. 101-19.

Iken, A., and others. 1983. The uplift of Unteraargletscher at the beginning of the melt season - a consequence of water storage at the bed? By A. Iken, H. Röthlisberger, A. Flotron, and W. Haeberli. Journal of Glaciology, Vol. 29, No. 101 , p. $28-47$.

Kamb, B. Unpublished. The role of rock friction in basal sliding of glaciers and the lubricating effect of basal water pressure. [Manuscript presented at Symposium on Glacier Beds, Ottawa, 15-19 August 1978.]

Kamb, B., and Echelmeyer, K.A. 1986. Stress-gradient coupling in glacier flow: I. Longitudinal averaging of the influence of ice thickness and surface slope. Journal of Glaciology, Vol. 32, No. 111, p. 267-84.

Lliboutry, L. 1968. General theory of subglacial cavitation and sliding of temperate glaciers. Journal of Glaciology, Vol. 7, No. 49, p. 21-58.

Raymond, C.F., and Malone, S. 1986. Propagating strain anomalies during mini-surges of Variegated Glacier, Alaska, U.S.A. Journal of Glaciology, Vol. 32, No. 111, p. $178-91$

Raymond, C.F., and Malone, S. Unpublished. Relationship of directly observed basal sliding rate to variations in surface velocity, strain rate, and seismic activity. Geophysics Program, University of Washington. Progress report for NSF grant DPP79-03942.

Raymond, C.F., and others. Unpublished. Variegated Glacier Studies - 1979, by C.F. Raymond, W.D. Harrison, and E. Senear. [Available from World Data Center A for Glaciology.]

Röthlisberger, H. 1980. Gletscherbewegung und Wasserabfluss. Wasser, Energie, Luft, Jahrg. 72, Ht. 9, p. 290-94. 